\title{
Involuntary Attentional Orienting to Counterproductive Exogenous Cues
}

Word count: 10,492

\section{Sarina Evens}

Student number: 01003388

Promotor: Prof. Dr. Gilles Pourtois

Supervisor: Dr. Antonio Schettino

A dissertation submitted to Ghent University in partial fulfilment of the requirements for the degree of Master of Clinical Psychology

Academic year: 2016 - 2017

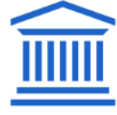




\section{Acknowledgements}

First and foremost, I would like to express my gratitude to my mentor, Antonio Schettino, for his ever present faith in me and for continuously challenging me. It was a pleasure to work with someone so contagiously enthusiastic. Thanks to you, my thesis was not only a very educational and most valuable experience that opened up a whole new world to me (shout-out to Bayes factors), but also a very enjoyable one. I appreciated the touch of humour hidden in your comments, the attention to detail, and the many helpful advises that made it possible for me to turn my thesis into something I am very proud of. I could not have wished for a better mentor, you are truly inspiring. I cannot thank you enough.

I would also like to thank my promotor, Gilles Pourtois, for giving me the opportunity to be a part of this exciting research project in the first place.

Furthermore, I would like to thank all the friends and family that have provided me with support and encouragement over the years. A special mention goes out to my dear friend Saskia Baes. A group assignment in our very first year of university was the start of a friendship I have grown to cherish. In the years that ensued, we have cried together and have celebrated together, and even in these last few weeks, I could always count on your support. Our joint library working-sessions were just what I needed to lift my spirits on low days and provide me with some fresh motivation. I would also like to thank Lucie Demolder, for some wonderful moments we have shared over the past few years. We have not been able to see much of each other lately, but my (and Saskia's) graduation will be a good excuse for us all to meet up again and celebrate (btw, we still have a to do list to finish!).

Last but not least, I want to thank my parents for giving me the best opportunities in life and giving me the freedom to discover and pursue my interests. You have patiently put up with me occupying the whole kitchen table with my notes and supported (and tolerated) me in my most stressed out moments. But most of all, thank you for always believing in me, even at times when I did not. 


\begin{abstract}
In the literature, there is an ongoing debate regarding the nature of attentional orienting towards non-reportable exogenous cues. Some argue that even though bottomup orienting can occur towards conscious stimuli, it is consistently modulated by endogenous factors in the case of unconscious stimuli. This would suggest that there may be no purely exogenous shifts of attention towards unconscious stimuli. In this thesis, we set out to provide compelling evidence for an automatic nature of attentional orienting towards non-reportable cues, independent from endogenous factors (e.g., attentional task set). To investigate this, an experiment employing the temporal order judgement (TOJ) paradigm was conducted, in which two line gratings of opposite orientation were presented on each side of a fixation, separated by various stimulus onset asynchronies (SOAs). Participants were required to report the orientation of the line grating that was presented first. In two-thirds of the trials, a non-reportable exogenous cue was presented on the opposite location of the first line grating, making it counterproductive to attend to the cue. Cue awareness was assessed in addition to performance on the TOJ task. Data were analysed using parametric and non-parametric procedures, supplemented by Bayes factor analyses. Results from these procedures converged in showing a robust bias towards the cued line gratings, suggesting that bottom-up orienting towards non-reportable exogenous cues occurs independently from attentional task set.
\end{abstract}




\section{Table of Contents}

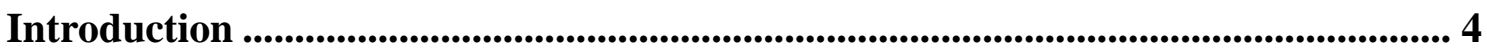

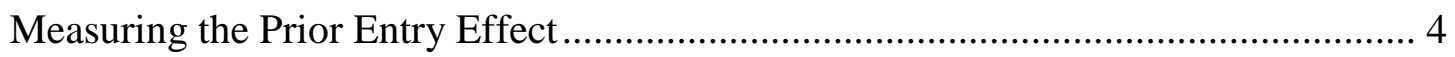

Endogenous versus Exogenous Attentional Orienting .............................................. 6

The Nature of Attentional Orienting towards Non-Reportable Exogenous Cues......... 7

Electrophysiological Evidence: Schettino et al. (2016) ............................................. 8

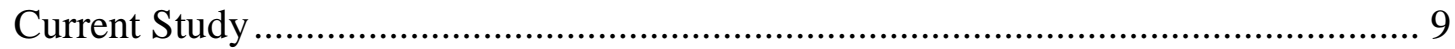

Materials and Methods ............................................................................................................ 10

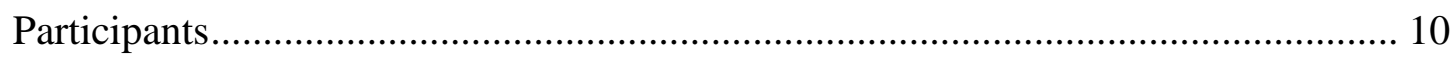

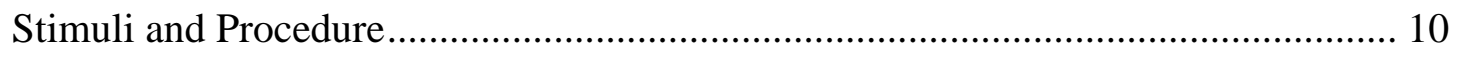

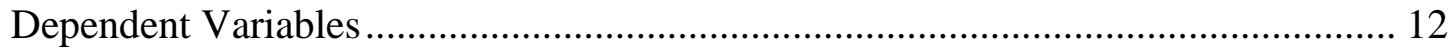

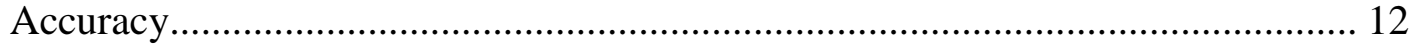

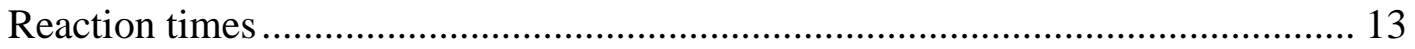

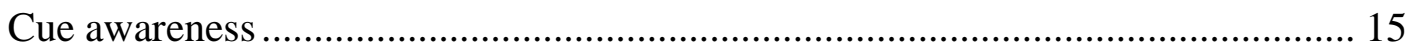

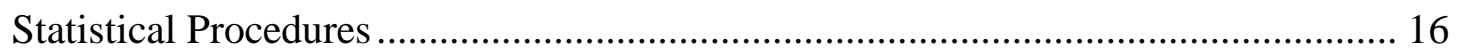

Results......................................................................................................................................... 18

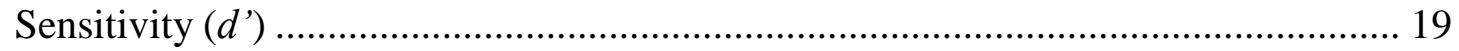

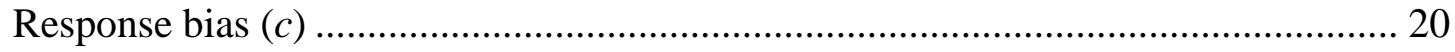

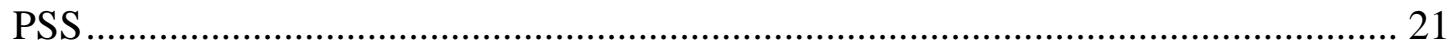

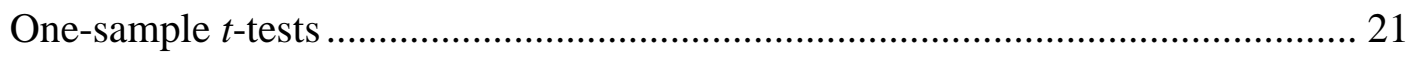

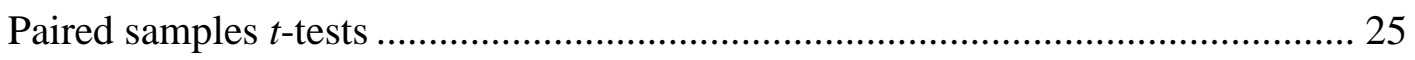

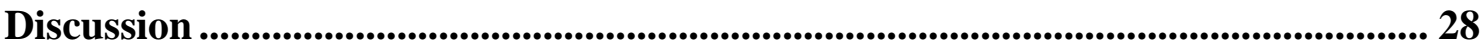

Nederlandstalige Samenvatting ........................................................................ 32

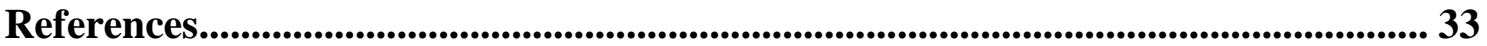




\section{Introduction}

In everyday life, we are constantly confronted with numerous stimuli giving us information about our environment. However, in order to function efficiently, we need to make a selection, only retaining the information that can prove useful for achieving our goals. Attention is a set of mechanisms that allow us to make this selection of objects, events, or locations in the environment (James, 1890; Posner, 1980). Especially important for this thesis is directing our attention to locations, referred to as spatial attentional orienting.

Attending to a spatial location can speed-up the relative arrival time of stimuli that are subsequently presented at that location (e.g., Eriksen \& Collins, 1969; Hughes, 1984; Shore, Spence, \& Klein, 2001; Spence \& Parise, 2010; Stelmach \& Herdman, 1991). This phenomenon is known as the law of prior entry, introduced by Titchener (1908). It states that attended stimuli reach consciousness more rapidly than unattended stimuli, suggesting that attention can speed-up perceptual processing.

\section{Measuring the Prior Entry Effect}

Examining the effects of attention on temporal perception has been problematic, since it is practically impossible for a person to indicate the exact moment when a stimulus or event was perceived as occurring. The solution that researchers came up with consists of using tasks that use judgement of relative timing of stimuli or events in comparison to one another. Two tasks are most frequently used to study the effect of attention on temporal perception: the simultaneity judgement (SJ) task and the temporal order judgement (TOJ) task (Spence \& Parise, 2010). In the SJ task, participants are asked to report whether two stimuli were presented simultaneously or not, while in the TOJ task they have to report which of two stimuli was presented first. In both tasks the stimulus onset asynchrony (SOA) between the two stimuli is varied across trials.

To get information about the prior entry effect in the context of TOJ tasks, the point of subjective simultaneity (PSS) is calculated. This is the SOA at which each response is given equally often, presumably because the two stimuli were perceived as being simultaneous. Comparing the PSS between the conditions in which the target stimulus is attended and conditions in which the target stimulus is unattended provides evidence for the prior entry effect. According to Titchener's law of prior entry, the attended stimulus 
needs to be presented later in time to be perceived as simultaneous to the unattended stimulus. This bias towards attended stimuli is especially visible at short SOAs, when uncertainty about onset times is higher (Spence \& Parise, 2010).

However, the problem with many studies using TOJ tasks is that there are several possible methodological confounds. Usually the prior entry effect is attributed to attentional modulation, but there is potentially also an influence of strategic decision criteria and response biases, as well as primary sensory facilitation (K. A. Schneider \& Bavelier, 2003).

Consider a TOJ task in which high-pitched or low-pitched tones are presented in either the right or the left ear, and the task requires to report whether the tone on the left or the right occurred first. Importantly, participants are also told that the first stimulus is more likely to occur in the left ear. In conditions of maximal uncertainty (i.e., at short SOAs), they will tend to minimize effort and, therefore, judge more often that the sound on the left appeared first. To reduce the influence of this bias, one can use an orthogonal-response paradigm (see Shore et al., 2001), meaning that attention is manipulated on a different dimension than the task-relevant dimension (see also Ansorge, Horstmann, \& Scharlau, 2011; Kiefer et al., 2011). In the example above, attention is manipulated on a spatial dimension (i.e., right or left) but, instead of using a spatial response dimension ("Which tone was first, the one on the left or right ear?"), participants could be asked to judge whether the high-pitched or the low-pitched tone occurred first. Another way to reduce response bias is by asking participants, in different experimental blocks, "Which stimulus came first?" and "Which stimulus came second?", and subsequently average their responses. One study (Frey, 1990) found prior entry for the unattended (instead of the attended) stimulus when observers were required to judge which stimulus appeared second, compared to when they reported which stimulus occurred first. However, in a subsequent study using the same experimental strategy (Shore et al., 2001), the authors only observed shorter PSS favouring the attended stimulus, suggesting that task-relevant factors can modulate prior entry effects but may not be strong enough to reverse it.

Another element to consider is sensory facilitation. In an exemplary experiment, Fendrich and Corballis (2001) presented a visual flash and an auditory click in temporal 
proximity and found that their perceived onset is shifted as to give the illusion that they occurred simultaneously. This effect is even more pronounced when two stimuli are presented in the same sensory modality and are perceptually similar ("illusory conjunction"; see Treisman \& Schmidt, 1982), because cue and target excite the receptive fields of the same neuronal population. However, attention is not necessary for this phenomenon to occur and, therefore, it should not be considered prior entry (K. A. Schneider \& Bavelier, 2003). This perceptual confound can nonetheless be avoided in at least two ways: (i) present cue and target in different sensory modalities, for example an auditory cue during a visual TOJ task that uses LED flashes as targets (McDonald, Teder-Sälejärvi, Di Russo, \& Hillyard, 2005); (ii) use cues that are perceptually very different from the targets, e.g., placeholder boxes as cues and horizontal/vertical lines as targets (Schettino, Loeys, \& Pourtois, 2013; Schettino, Rossi, Pourtois, \& Müller, 2016; Shore et al., 2001).

When all these sources of bias have been maximally reduced, we can assume that the residual effect is caused by genuine attentional modulation. Importantly, several studies have shown that, when these non-attentional confounds are minimized and carefully controlled, prior entry is still a robust attentional effect (Schettino et al., 2013, 2016; Spence \& Parise, 2010; Tünnermann, Petersen, \& Scharlau, 2015; Tünnermann \& Scharlau, 2016).

\section{Endogenous versus Exogenous Attentional Orienting}

The cues in the TOJ tasks prompt participants to shift their attention, but there are two ways in which this orienting can happen (Corbetta \& Shulman, 2002; Egeth \& Yantis, 1997; Posner, 1980; Posner, Snyder, \& Davidson, 1980). The first is referred to as top-down or endogenous attentional orienting and consists of voluntarily directing our attention according to our goals and intentions. This can be induced by providing prior information about the most probable location of a target. Based on this prior information, participants set up an attentional task set that guides shifts of spatial attention. The second way consists of involuntarily orienting attention irrespective of our goals or intentions. This is referred to as bottom-up or exogenous attentional orienting (Serences et al., 2005; Theeuwes, 1994). This can be elicited by the peripheral presentation of a non-predictive cue stimulus. So, in order to be purely exogenous, the 
cue should be uninformative and unpredictable. Stimuli used for capturing exogenous attention are usually salient because of their sudden presentation against a static background of no-changing objects. They have the ability to automatically grasp attention, even though the observer had no intention to do so. These stimuli are often referred to as having abrupt onsets or transients.

\section{The Nature of Attentional Orienting towards Non-Reportable Exogenous Cues}

It is not necessarily the case that these abrupt onsets are perceived consciously. For a visual stimulus to be perceived consciously, there are two processes that must be successfully executed: a consolidation process of representations within the visual system, followed by a post-sensory gating process, which determines whether consolidated stimuli will be encoded into working memory based on active task sets. If one of these processes fails to be completed, the stimulus remains unconscious (Kiefer et al., 2011). Previous studies have suggested that exogenous attention might be a process which is independent of awareness and intentions (Mulckhuyse \& Theeuwes, 2010). However, there is an ongoing debate regarding the exact nature of the attentional capture of exogenous stimuli (e.g., abrupt onset stimuli). Folk, Remington and Johnston (1992) found that orienting towards exogenous cues only occurs when there is a match between the cue features and the top-down controlled search template for task-relevant features (i.e., attentional task set). This would suggest endogenous orienting, since topdown feature selection precedes attentional orienting. Conversely, it is reasonable to state that even though the attentional shifts are modulated by endogenous factors, they are still driven by external stimuli to some extent, making them exogenous given the external stimuli and pre-established attentional task set. According to Ansorge et al. (2011), to be able to call into question purely exogenous orienting, there must be a lack of a suited endogenous feature-specific search criterion as a prerequisite for an orienting effect. In accordance with this criterion, support has been found for exogenous orienting towards reportable stimuli, but not for non-reportable stimuli, thereby making visual awareness an important prerequisite for this phenomenon (see also Kiefer et al., 2011; but see McCormick, 1997; Mulckhuyse, Talsma, \& Theeuwes, 2007). 


\section{Electrophysiological Evidence: Schettino et al. (2016)}

A recent study by Schettino et al. (2016) showed compelling and automatic stimulusdriven attentional orienting towards non-reportable exogenous cues. They investigated the prior entry effect and its electrophysiological correlates using event-related potentials (ERPs) in a visual TOJ task. The main advantage of ERPs is that they offer more direct evidence, with a millisecond temporal resolution, of the neural systems involved in prior entry mechanisms (Shore et al., 2001; Spence \& Parise, 2010; Vibell, Klinge, Zampini, Spence, \& Nobre, 2007). They also make it possible to disentangle perceptual from post-perceptual or decision-based mental processes. These authors exploited the well-documented effect that amplitude and latency modulations of lateralized early electrophysiological brain responses reflect increased neural activity related to the target in ventral and dorsal extrastriate visual areas (Di Russo, Martínez, \& Hillyard, 2003). Modulations of these early components would suggest that, even before the activation of response-related networks, attentional orienting may actively bias visual perception.

In the ERP study performed by Schettino et al. (2016), participants were asked to report the temporal order of horizontal and vertical line gratings appearing on the left and right hemifield. These stimuli were separated in time by various SOAs. In some trials, an uninformative exogenous cue could precede either the first or the second line grating (compatible and incompatible conditions, respectively) with equal probability. This cue was presented only briefly (i.e., $20 \mathrm{~ms}$ ) to prevent conscious perception, making it a priori non-reportable. The authors focused on the N1pc component, a lateralized occipital negative deflection starting around $120 \mathrm{~ms}$ after stimulus onset, signalling the initial orienting of attention along the horizontal meridian (Verleger, Żurawska vel Grajewska, \& Jaśkowski, 2012). They conducted two versions of the experiment in which they differentially manipulated prior knowledge of the cue, in order to examine the effect of attentional task set on stimulus-driven attentional capture. In Experiment 1, participants were informed that a cue could be presented, but that it would be of no use to them. Cue awareness was tested in a proportion of the trials. In Experiment 2, participants would remain uninformed of the presence of a cue, until revealed at the end of the session. After analysis, there appeared to be no behavioural or 
electrophysiological differences between the two experiments, suggesting no influence of attentional task set on initial attentional orienting.

The behavioural results of this experiment showed that the cued line gratings were consistently perceived as appearing first, with no bias towards any of the line gratings in the no cue condition. Based on these results it was concluded that there was a robust bias towards the stimulus that was presented at the cued location. This bias was especially clear at short SOAs. The ERP results showed that the N1pc was smaller in compatible relative to incompatible trials because, in the former condition, cue and target shared the same spatial location and therefore attentional reorienting was not necessary (Fu, Greenwood, \& Parasuraman, 2005; Wascher \& Beste, 2010). Importantly, the N1pc also peaked earlier after target onset in compatible relative to incompatible trials, suggesting acceleration of sensory processing at cued locations. In conclusion, Schettino et al. (2016) found evidence for a stimulus-driven acceleration of sensory processing in the visual modality, independent from top-down attention allocation.

\section{Current Study}

In this thesis, we aim to provide even stronger evidence for the hypothesis that bottom-up attentional orienting towards non-reportable exogenous cues is truly a compelling and automatic process that we cannot - or is at least very difficult to suppress. To investigate this, we used a behavioural experiment consisting of a visual orthogonal TOJ task, adapted from Schettino et al. (2016). Participants had to report the temporal order in which they perceived horizontal and vertical line gratings, separated by various SOAs. On uninformative trials, no cues were presented. On informative trials, the line gratings were preceded by one informative exogenous cue, either on the left or the right of the fixation. The cue only appeared for a very short period of time, making it non-reportable (cue awareness was tested on a proportion of the trials). Importantly, the cue was always informative as it predicted where the target stimulus was not going to be located (i.e., the cued location is consistently opposite of the location of the first line grating), making it counterproductive for participants to shift their attention towards the cued location (for a similar reasoning, see Hickey, Chelazzi, 
\& Theeuwes, 2010; Hickey \& van Zoest, 2013). If attentional task set plays a role, we would expect participants to be able to ignore the cue (Ansorge \& Neumann, 2005; Held, Ansorge, \& Müller, 2010; Scharlau \& Ansorge, 2003) and, therefore, no bias towards the cued location would be observed, suggesting an endogenous nature of the orienting response (Ansorge et al., 2011; Folk et al., 1992). However, we expected to find an attentional bias towards the targets that were preceded by the non-reportable exogenous cues even though they were counterproductive, suggesting that this must be an automatic response that cannot be easily suppressed.

\section{Materials and Methods}

\section{Participants}

A total of 21 volunteers participated in the experiment $(20 \mathrm{~F} / 1 \mathrm{M}$, median age 22 , range 18-36). Three participants were excluded from the final dataset due to poor behavioural performance, which was a priori defined as a PSS larger than the longest SOA (in our case, $217 \mathrm{~ms}$; for a similar procedure, see Schettino et al., 2013; Weiß \& Scharlau, 2012). After exclusion, we had a total final sample of 18 participants (18 women, median age 22, range 18-36). Informed consent was obtained for all participants. All volunteers were right-handed, had normal or corrected-to-normal vision, and no history of neurological or psychiatric disorders. All participants received a monetary compensation of $10 €$ for their participation.

\section{Stimuli and Procedure}

The experimental paradigm is an adaptation of Experiment 1 in Schettino et al. (2016). It was conducted on a monitor with screen resolution of $1028 \times 768$ pixels and $60 \mathrm{~Hz}$ refresh rate. Stimulus presentation was controlled with E-Prime 2.0 (W. Schneider, Eschman, \& Zuccolotto, 2002). Each trial started with a central fixation cross (degrees of visual angle: $0.96^{\circ} \times 0.96^{\circ}$ at $80 \mathrm{~cm}$ viewing distance) and two placeholders $\left(4.77^{\circ} \times 2.86^{\circ}\right)$ located on the left and right side of fixation $\left(3.10^{\circ}\right.$ of eccentricity along the horizontal meridian), displayed on a white background (Figure 1). 
After $2000 \mathrm{~ms}$, in two-thirds of the trials, one of the placeholders ${ }^{1}$ (either left or right, with equal probability) got thicker - from 5 to 7 pixels - for $17 \mathrm{~ms}$. Thirty-four ms after cue offset, a line grating enclosed in an oval frame (identical to Schettino et al., 2016; see also Schettino et al., 2013, Experiments 4-5) appeared in the placeholder opposite to the cued hemifield. The orientation of the lines in the first grating was either horizontal or vertical, with equal probability. The second line grating (whose lines were always of opposite orientation relative to the first one) appeared in the other placeholder after a variable $\operatorname{SOA}(217,150,83,17$ or $0 \mathrm{~ms})$. Both line gratings remained on screen for 100 ms, before being simultaneously masked until response. The mask was obtained by randomly shuffling the pixels of the original stimulus. In a two-alternative forced-choice task, observers were instructed to judge the orientation ${ }^{2}$ of the grating appearing first by pressing numbers 2 or $8^{3}$ (counterbalanced across participants) on a standard numeric pad of a USB keyboard. Four-hundred and seventy trials were randomly intermixed in 10 blocks (47 trials each) of the experimental task, preceded by verbal and written instructions as well as a practice block (with feedback) containing 20 trials.

\footnotetext{
${ }^{1}$ We chose this particular cue because it is not perceptually similar to the targets, to avoid "illusory conjunction" confounds (Treisman \& Schmidt, 1982; see also Introduction). Given this perceptual dissimilarity, any influences of top-down attentional task sets (i.e., orienting is conditional on prior feature selection) on purely bottom-up attentional capture are avoided. This is particularly relevant because the cue was presented below the threshold of subjective awareness (Ansorge et al., 2011; Kiefer et al., 2011).

${ }^{2}$ By choosing a discrimination task instead of a simple detection task, the influence of top-down attentional task sets can further be reduced. In a simple detection task, participants would have to judge whether the first target appeared on the left or the right hemifield, meaning that attention would be directed towards the target's location, whereas in this discrimination task participants' attention is being directed towards different features of cue and target (i.e., thickness in the former, orientation in the latter) (Folk et al., 1992; see also Introduction).

${ }^{3}$ We used an orthogonal-response paradigm, i.e. response buttons were located on the vertical axis, whereas the stimuli were presented on the horizontal axis (see also Schettino et al., 2013). This allowed us to further attenuate stimulus-response compatibility effects, which are known to markedly affect the behavioural outcome of TOJ tasks (K. A. Schneider \& Bavelier, 2003; Shore et al., 2001; see also the classical Simon effect: Hommel, 2011; Simon \& Rudell, 1967).
} 


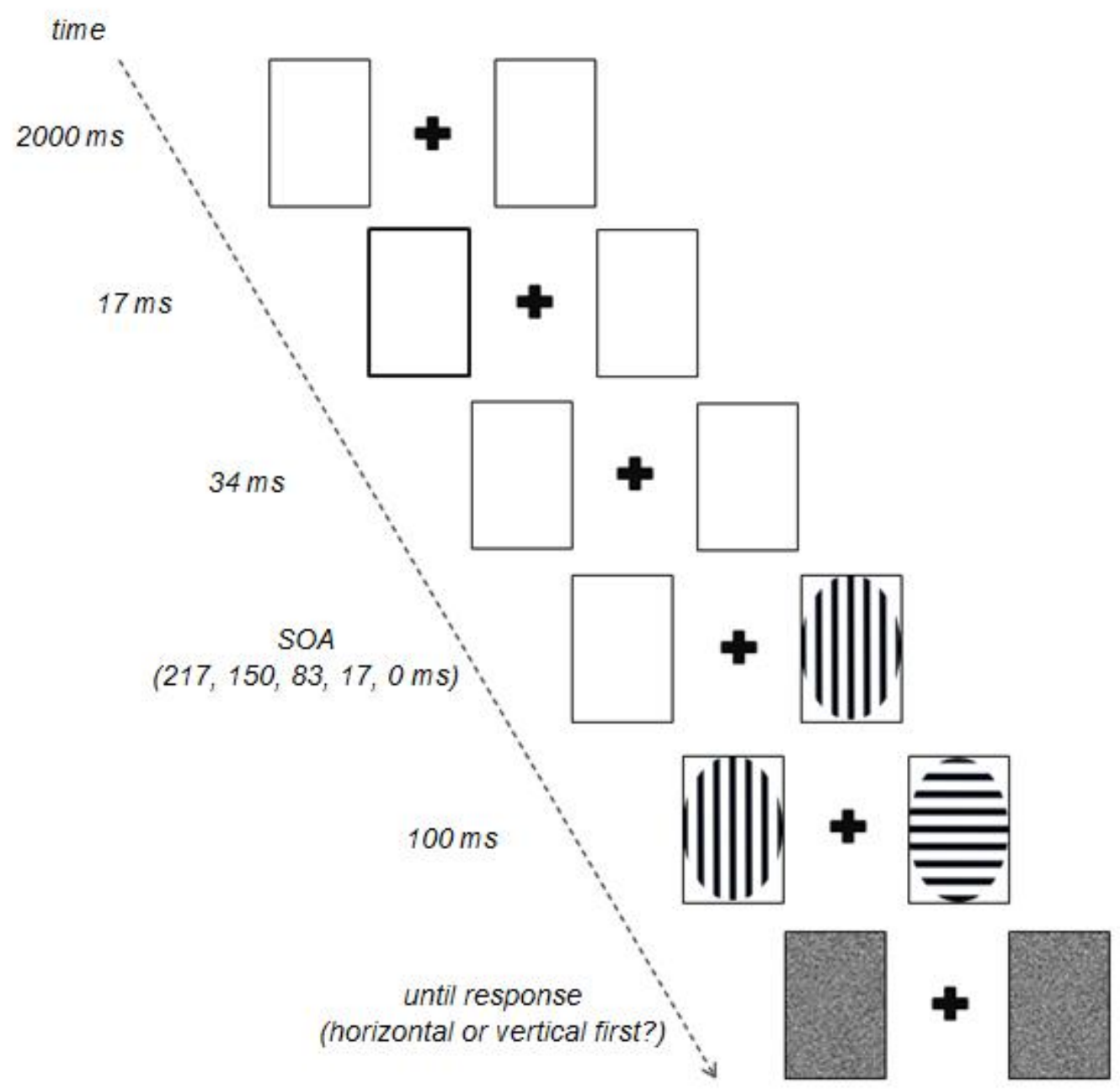

Figure 1. Prototypical trial of the experimental procedure. Adapted from Schettino et al. (2016).

\section{Dependent Variables}

\section{Accuracy}

Accuracy on the TOJ task is expressed as the proportion of horizontal first responses (Shore et al., 2001). This means that positive SOAs indicate trials in which the horizontal line grating was presented first, whereas negative SOAs indicate that the vertical line grating was presented first (Figure 2). Trials in which responses occurred $2000 \mathrm{~ms}$ after the onset of the masks were excluded $(M=4.96 \%, S E=0.36)$. In this study, we are interested in participants' performance on the TOJ task as well as their awareness of the exogenous cue. To investigate their performance, we calculated the PSS. PSS is the SOA at which each response is given equally often. Individual PSSs were obtained by: (i) converting the proportion of horizontal first responses into $z$ - 
scores using a standardized normal distribution; (ii) calculating the slope and intercept of the best-fitted linear regression on these $z$-scores; (iii) calculating the PSS according to the formula: PSS = -intercept/slope (see Moseley, Gallace, \& Spence, 2009). To assess prior entry effects, the PSS values were compared against 0 with two-tailed onesample $t$-tests. Additionally, two-tailed paired samples $t$-tests were conducted to compare the PSS values in the no cue condition with the PSS values in the horizontal first condition (vertical line grating was cued) and the vertical first condition (horizontal line grating was cued), respectively.

\section{Reaction times}

Visual inspection of the distribution of the mean reaction times for each condition as a function of SOA (Figure 3) confirms that participants were faster at long SOAs and slower at short SOAs, i.e., when uncertainty was maximal. In the no cue condition, the SOA at which response times were the slowest is 0 . This point seems to shift in cued conditions, with slowest reaction times at SOA $83 \mathrm{~ms}$. This dependent variable, however, is not analysed statistically, since previous studies have already established the unreliability of reaction time for the assessment of prior entry effects (Schettino et al., 2013; Shore et al., 2001; Sternberg \& Knoll, 1973), especially in TOJ tasks because the experimenter does not typically stress the importance of response speed, but only accuracy. 


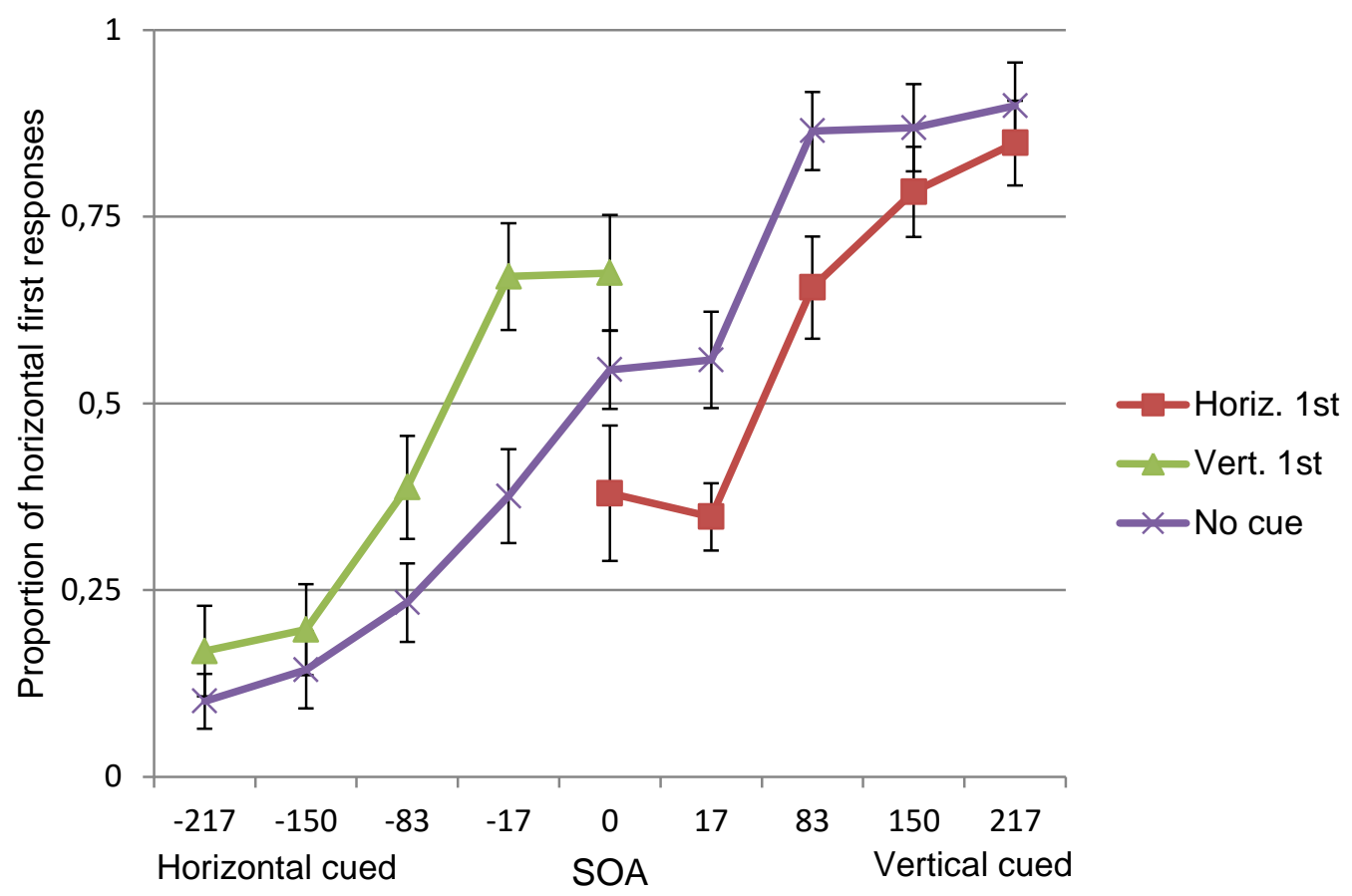

Figure 2. Results. Accuracy is defined as the proportion of horizontal first responses. Displayed is the mean proportion of horizontal first responses for each cue condition, as a function of SOA. The vertical bars indicate the standard deviation $(S D)$.

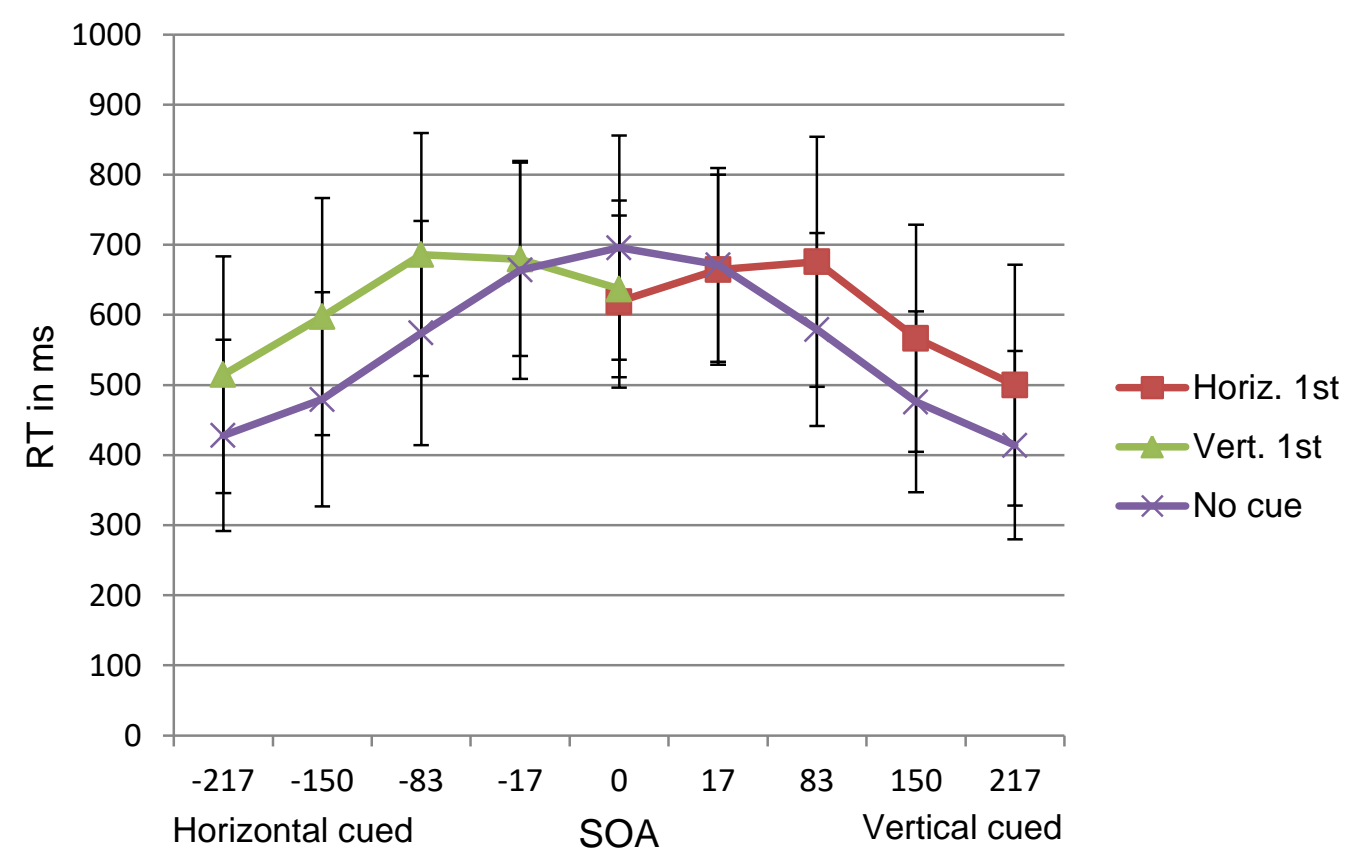

Figure 3. Results. Distribution of mean reaction times, separately for each cue condition, across stimulus onset asynchronies (SOAs). Vertical bars represent standard deviation $(S D)$. 


\section{Cue awareness}

Cue awareness was assessed in $8.09 \%$ (38 out of 470) of the trials (equally distributed across cue and no cue conditions). Three questions were presented in these trials after the TOJ response: (Q1) have you seen the cue? [yes/no]; (Q2) was it on the left or right? If you have not seen it, please guess [left/right]; (Q3) how clear was it? [4-point Perceptual Awareness Scale, PAS (Ramsøy \& Overgaard, 2004)]. For this thesis, we focussed only on responses to Q1.

Sensitivity and response bias were analysed in the framework of signal detection theory (Green \& Swets, 1966; Stanislaw \& Todorov, 1999). Sensitivity (d') was used to calculate participants' ability to discriminate signal from noise, i.e., to verify whether participants could reliably detect the exogenous cue when presented. The $d^{34}$ was calculated by subtracting the $z$-score that corresponds to the false-alarm rate (the probability of responding yes on no cue trials, indicated as $F$ ) from the $z$-score that corresponds to the hit rate (the probability of responding yes on cued trials, indicated as $H$ ), using the following formula in Excel: DPRIME $=\operatorname{NORMSINV}(\mathrm{H})-$ NORMSINV(F) (Stanislaw \& Todorov, 1999). $d$ ' mathematically ranges from $-\infty$ to $+\infty$. A $d$ ' value of 0 indicates an inability to distinguish cue from noise, whereas positive values show a progressively increasing ability to detect the cue. A one-tailed one-sample $t$-test of the $d$ ' values against 0 was performed to verify participants' ability to detect the cue.

Response bias, i.e., the general tendency of participants to respond yes or no on Q1, was calculated using $c$. The $c$ is defined as the distance between the criterion (the value of the decision variable that is sufficiently high for a subject to answer yes to having seen a cue) and the point at which no response is favoured, also called the neutral point. The $c$ is calculated by adding the $z$-score that corresponds to the hit rate to the $z$-score that corresponds to the false-alarm rate, dividing that result by 2 and taking the negative

\footnotetext{
${ }^{4}$ Due to the relatively low number of trials in which cue awareness was assessed, hit or false alarm rates of 0 or 1 were not uncommon. These extreme values are problematic since their corresponding $z$-scores are $-\infty$ and $+\infty$, respectively. To deal with these extreme values, the loglinear approach was applied to the data before calculation of these rates. This approach consists of adding 0.5 to the number of hits and the number of false alarms, and adding 1 to both the number of signal trials and the number of noise trials (Hautus, 1995; Stanislaw \& Todorov, 1999).
} 
value of the resulting outcome. The following formula in Excel was used: $\mathrm{C}=$ $(\operatorname{NORMSINV}(\mathrm{H})+\operatorname{NORMSINV}(\mathrm{F})) / 2$ (Stanislaw \& Todorov, 1999). A negative $c$ value indicates a bias towards responding yes, whereas a positive $c$ value indicates a bias towards responding no. We evaluated whether participants showed a bias towards either of the two responses by comparing the $c$ values against 0 in a two-tailed onesample $t$-test.

\section{Statistical Procedures}

Given the modest sample size, Shapiro-Wilk's test was chosen to assess whether the data were normally distributed (Shapiro \& Wilk, 1965). For all $t$-tests, $p$-values, effect sizes, and confidence intervals around mean differences are reported. All $t$-tests were integrated by bootstrapped (5,000 samples with replacement) bias-corrected and accelerated 95\% confidence intervals of mean differences (Efron, 1987; Efron \& Tibshirani, 1993). These classical statistical analyses were performed using IBM SPSS v23 (https://www.ibm.com/analytics/us/en/technology/spss/). As a non-parametrical alternative to the $t$-test, Wilcoxon signed-rank tests (Wilcoxon, 1945) were carried out using JASP v0.8.1.2 (https://jasp-stats.org/download/). Pearson's $r$ was used as a measure of effect size for parametric and non-parametric tests (Cohen, 1992; Lakens, 2013). Additionally, Bayesian factor analyses were performed (also using JASP v0.8.1.2), given the fundamental problems associated with null hypothesis significance testing (NHST) briefly described below.

NHST procedures do not allow to quantify evidence in favour of the null hypothesis: one can only ever reject a null hypothesis or withhold judgement, but never accept it ${ }^{5}$ (Dienes, 2011; Etz, Gronau, Dablander, Edelsbrunner, \& Baribault, 2017; Gigerenzer, 2004; Rouder, Speckman, Sun, Morey, \& Iverson, 2009; Wagenmakers, 2007; Wetzels et al., 2011). However, within Bayesian inferential statistics, a measure is provided that can quantify whether the collected evidence is more consistent with the null hypothesis $\left(H_{0}\right)$ or the alternative hypothesis $\left(H_{1}\right)$ : the Bayes factor $(B F)$. The $B F$ provides us with

\footnotetext{
${ }^{5}$ In addition to not being able to state evidence in favour of the null hypothesis when using NHST procedures, evidence against the null hypothesis tends to get overestimated, because of a lack of consistency when the null is true (Rouder et al., 2009). In an empirical comparison of $855 t$-tests, it was found that approximately $70 \%$ of experimental effects with a $p$-value between .01 and .05 is associated with a default Bayes factor that indicates merely "anecdotal" evidence in favour of the alternative hypothesis (Wetzels et al., 2011). This indicates a substantial difference in the assessment of the strength of evidence.
} 
the relative plausibility of hypotheses based on the data, instead of the other way around as in NHST (Wagenmakers, 2007). Essentially, the $B F$ is an odds ratio that depicts the probability of the data under a certain hypothesis relative to that under another hypothesis (Dienes, 2011). This allows for a clear interpretation. For instance, $B F_{01}=2$ indicates that the data are twice as likely under $H_{0}$ than under $H_{1}$. As a guideline for the verbal interpretation of the evidential impact of the $B F$, we used the convention suggested by Raftery (1995) as described in Table 3 of Wagenmakers (2007) (see Table $1)$.

Table 1.

Interpretation of the Bayes factors (BFs)

\begin{tabular}{lll}
\hline Bayes Factor $\boldsymbol{B \boldsymbol { F } _ { \mathbf { 0 1 } }}$ & $\boldsymbol{P r}\left(\boldsymbol{H}_{\mathbf{0}} \mid \mathbf{D}\right)^{\mathrm{a}}$ & Evidence \\
\hline $1-3$ & $.50-.75$ & Weak \\
$3-20$ & $.75-.95$ & Positive \\
$20-150$ & $.95-.99$ & Strong \\
$>150$ & $>.99$ & Very strong \\
\hline
\end{tabular}

Note. Adapted from Wagenmakers (2017, p. 791).

${ }^{\text {a }}$ Probability of a specific hypothesis (here, $H_{0}$ ) being true given the data.

These advantages of a Bayesian inference approach over NHST support our decision of adding $B F s$ as an alternative to $p$-values. For the calculation of $B F s$, a prior on the standardized effect size was set as a Cauchy distribution (similar to a normal distribution but with heavier tails) with location at 0 and scaling factor of $r=0.707$. This Cauchy (also termed Jeffrey-Zellner-Siow, JZS) prior is a reasonable default prior, since it conveys a minimum degree of information (Rouder et al., 2009). For this prior, a scaling factor of $r=0.707$ was chosen for the prior width of the distribution. This means that the effect size has a prior probability of $50 \%$ to be between -0.707 and 0.707 (the interquartile range). Choosing a narrower distribution (i.e., a lower value of $r$ ), would result in a high level of similarity between $H_{1}$ and $H_{0}$, making the tests uninformative. Conversely, choosing an unreasonably wide distribution would result in the $B F$ favouring the null too heavily, by placing too much weight on extreme effect size values (Etz et al., 2017; Rouder et al., 2009; Wagenmakers et al., 2017). In addition to calculating the $B F$, robustness checks and sequential analyses (combined with a robustness analysis) of the $B F$ were carried out and visualized in plots. Robustness 
analyses serve to quantify the evidential impact of the prior width on the $B F$. If reasonable variations to the prior width do not affect the qualitative conclusion of the evidence, we can conclude that the result is fairly robust. Sequential analyses visualize the evidential flow with the accumulation of every data point collected.

\section{Results}

Due to a coding error in E-Prime, we were unable to use the data from five conditions $^{6}$. However, we could estimate the responses and reaction times of the erroneous conditions based on the distribution of the data of five similar conditions ${ }^{7}$ using multiple imputations via bootstrapped expectation-maximization algorithm (Honaker \& King, 2010) using the package Amelia v1.7.4 (Honaker, King, \& Blackwell, 2009) in $R$ v3.3.2 (R Core Team, 2015).

For an overview of the means and standard errors of the dependent variables $\left(d^{\prime}, c\right.$, and the PSS) see Table 2.

Table 2.

Mean and Standard Error Values of d', c, and PSS across Cue Conditions.

\begin{tabular}{lcl}
\hline Dependent Variable & $\boldsymbol{M}$ & $\boldsymbol{S E}$ \\
\hline$d^{\prime}$ & 0.08 & 0.13 \\
$c$ & 1.25 & 0.15 \\
PSS No Cue & -8.71 & 6.91 \\
PSS Horizontal First & 41.1 & 8.30 \\
PSS Vertical First & -60.8 & 10.3 \\
\hline
\end{tabular}

\footnotetext{
${ }^{6}$ The conditions affected were the following: (i) SOA $150 \mathrm{~ms}$, no cue, vertical lines appeared first on the left hemifield; (ii) SOA $83 \mathrm{~ms}$, no cue, vertical lines appeared first on the left hemifield; (iii) SOA $17 \mathrm{ms,}$ no cue, vertical lines appeared first on the left hemifield; (iv) SOA $0 \mathrm{~ms}$, cue appeared on the right hemifield, vertical lines appeared on the left hemifield; (v) SOA 0 ms, cue appeared on the left hemifield, horizontal lines appeared on the right hemifield.

${ }^{7}$ The conditions used to estimate the lost data were the following: (i) SOA $150 \mathrm{~ms}$, no cue, vertical lines appeared first on the right hemifield; (ii) SOA $83 \mathrm{~ms}$, no cue, vertical lines appeared first on the right hemifield; (iii) SOA $17 \mathrm{~ms}$, no cue, vertical lines appeared first on the right hemifield; (iv) SOA $0 \mathrm{~ms}$, cue appeared on the right hemifield, vertical lines appeared on the right hemifield; (v) SOA $0 \mathrm{~ms}$, cue appeared on the left hemifield, horizontal lines appeared on the left hemifield.

The only difference between the lost conditions and the ones above was the hemifield of presentation of the first target. We assumed similar accuracy distributions because previous studies never showed behavioural differences based on the hemifield of presentation (Schettino et al., 2013; Schettino et al., 2016).
} 


\section{Sensitivity ( $d$ ')}

Shapiro-Wilk's test of normality indicated that the null hypothesis (i.e., the observed $d$ ' values follow a normal distribution) could not be rejected $(W=.92, p=.107)$. Assuming normality, a one-tailed one-sample $t$-test indicated that there was no statistically significant evidence that participants could detect the exogenous cue when presented $\left(t_{17}=0.58, p=.277, r=.14, \mathrm{CI}_{.95}[-0.16,0.33]\right)$. However, given the problems associated with $p$-values mentioned earlier, we could not exclude the possibility of a deviation from normality. For this reason, we decided to also perform a non-parametric test. Nonetheless, even when normality was not assumed, we still did not find statistically significant evidence that participants were able to detect the cue $(T=85, p=$ $.517, r=-.004)$.

A Bayesian one-tailed one-sample $t$-test on $d$ ' values showed that the data was 2.51 times better explained by the null hypothesis than by the alternative hypothesis $\left(B F_{01}=\right.$ $2.51 \pm 0.01 \%$ ) (Figure $4 A$ ). This means it is more likely that the participants were not able to detect the cue when presented. While this result provides only weak evidence for $H_{0}$, a robustness check shows that even with an increasingly wider prior, there is only anecdotal to moderate evidence in favour of the null hypothesis (Figure 4B). Sequential analysis shows that even after just a few participants, the $B F$ quickly stabilizes and remains stable with an increasing number of participants (Figure $4 C$ ). 
A.

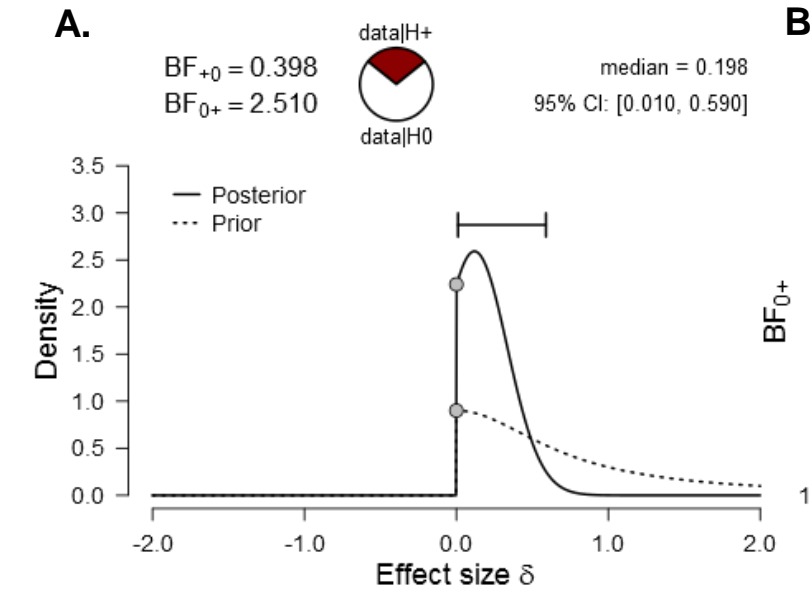

Note. Prior and posterior distribution of the

Bayes factor $(B F)$

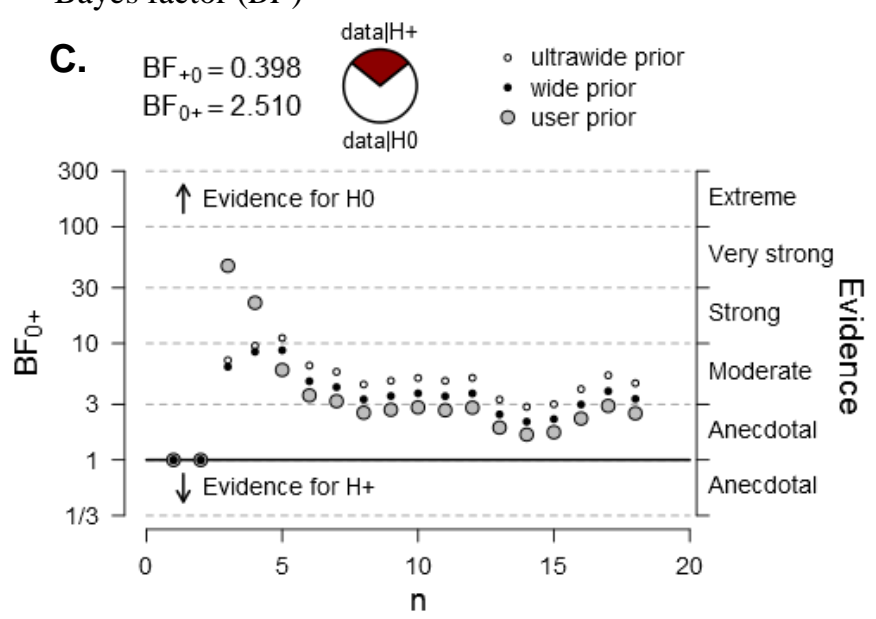

Note. Sequential analysis (combined with robustness check) of the Bayes factor $(B F)$

Figure 4. Bayesian one-sample $t$-test of sensitivity $\left(d^{\prime}\right)$.

\section{Response bias $(c)$}

Shapiro-Wilk's test showed that the null hypothesis of normality should be rejected $(W=.89, p=.045)$. A two-tailed one-sample $t$-test on $c$ values showed statistically significant evidence for a bias towards responding $n o\left(t_{17}=7.82, p<.001, r=.88, \mathrm{CI}_{.95}\right.$ $[0.95,1.54])$. The results of a nonparametric Wilcoxon signed-rank test pointed in the same direction $(T=168, p<.001, r=.60)$.

A Bayesian one-sample $t$-test showed that the data are 34,006 times more probable under $H_{1}$ than under $H_{0}\left(B F_{10}=34,006 \pm 0.00 \%\right)$, indicating very strong evidence in favour of the hypothesis that there is a bias: here, a bias towards responding no (Figure 
$5 A)$. A $B F$ robustness check showed that this result is very robust to changes in the prior width (Figure $5 B$ ). Sequential analysis showed a steady increase of the $B F$ with every new data point (Figure 5C).

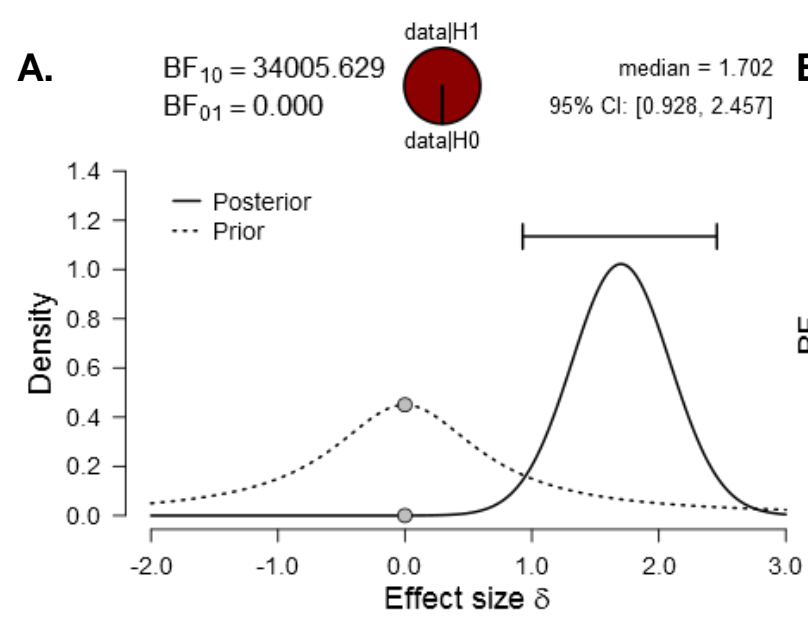

Note. Prior and posterior distribution of the Bayes factor $(B F)$

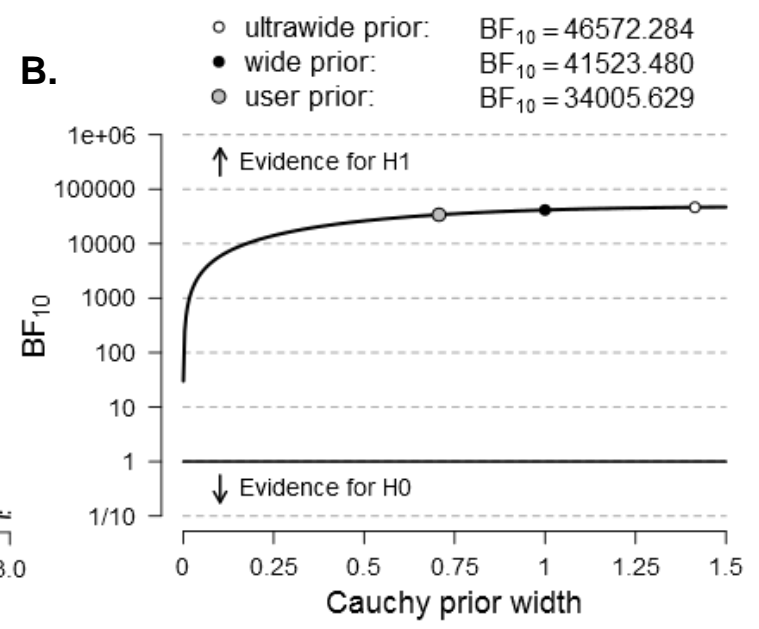

Note. Bayes factor $(B F)$ robustness check

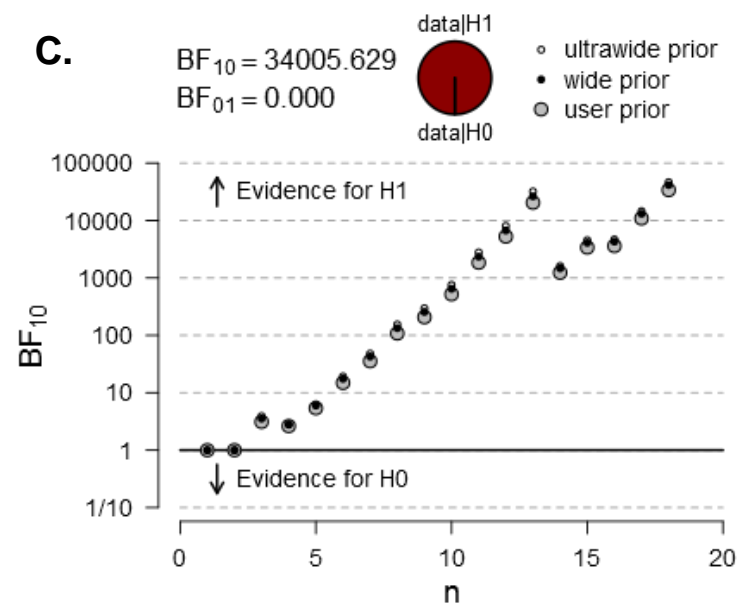

Note. Sequential analysis (combined with robustness check) of the Bayes factor $(B F)$

Figure 5. Bayesian one-sample $t$-test of response bias (c).

\section{PSS}

\section{One-sample $t$-tests}

Tests of normality were performed for all conditions, showing only statistically significant evidence for a violation of normality in the vertical first condition (no cue: $W$ $=.98, p=.878$; horizontal first: $W=.96, p=.570$; vertical first: $W=.88, p=.028$ ). Two-tailed one-sample $t$-tests revealed that cued line gratings were consistently 
perceived as appearing first (horizontal first: $t_{17}=4.82, p<.001, r=.76, \mathrm{CI}_{.95}[25.2$, 56.3]; vertical first: $\left.t_{17}=-5.71, p<.001, r=.81, \mathrm{CI}_{.95}[-81.7,-42.2]\right)$, whereas no statistically significant bias was found when no cue was presented $\left(t_{17}=-1.22, p=.244\right.$, $r=.28, \mathrm{CI}_{.95}[-22.2,5.66]$ ) (Figure 6). Wilcoxon signed-rank tests provided us with similar results (horizontal first: $T=159, p<.001, r=.53$; vertical first: $T=3.68, p<$ $.001, r=-.61 ;$ по сие: $T=52, p=.154, r=-.24)$.

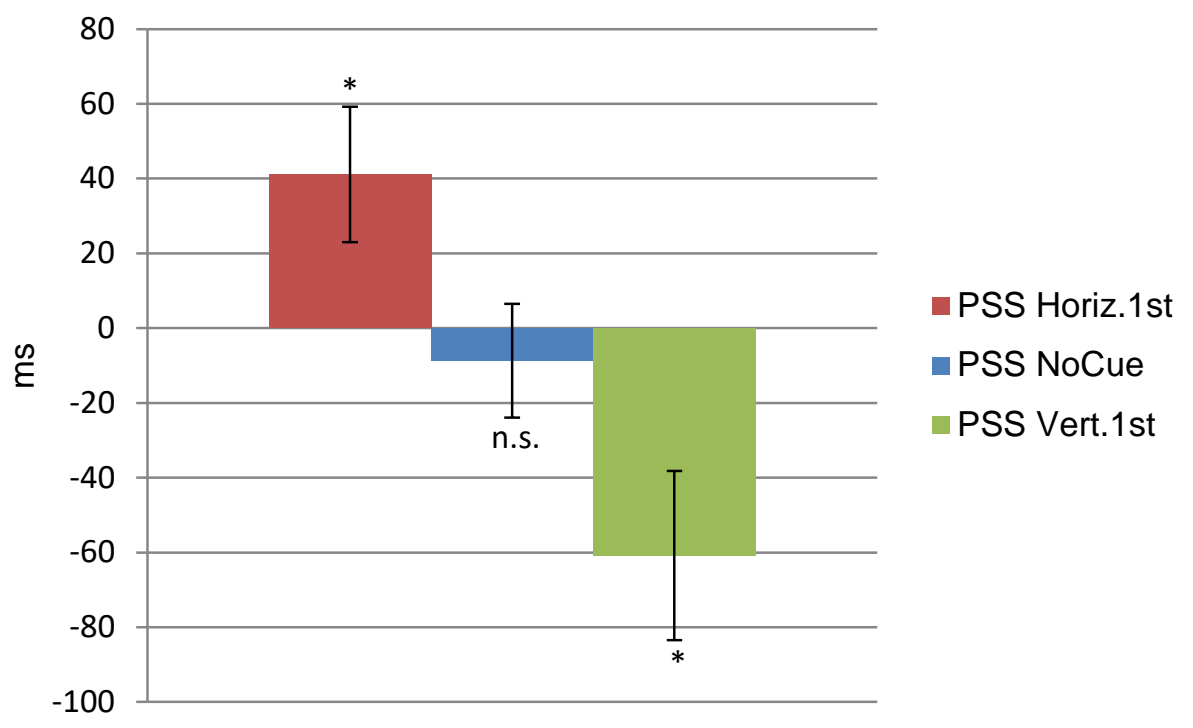

Figure 6. Results. Mean point of subjective simultaneity (PSS) values for each cue condition. PSS values that significantly differ from 0 indicate the prior entry effect.

Bayesian analysis of the PSS in the no cue condition against 0 slightly favoured the null hypothesis over the alternative hypothesis $\left(B F_{01}=2.17 \pm 0.004 \%\right)$ (Figure $\left.7 A\right)$. A robustness check reveals that, as the prior width increases, the evidence in favour of the null hypothesis does as well. Still, over a wide range of plausible values for the prior width, the data provide only anecdotal to moderate evidence in favour of the null hypothesis (Figure $7 B$ ). In a sequential analysis, we can observe a stable $B F$ that no longer seems to increase or decrease as the data accumulates (Figure $7 \mathrm{C}$ ). Analysis of the PSS in the horizontal first and in the vertical first conditions showed very strong evidence in favour of the alternative hypothesis compared to the null hypothesis (horizontal first: $B F_{10}=186 \pm 0.00$; vertical first: $B F_{10}=953 \pm 0.00$ ). Inspection of the respective posterior distributions reveals a positive effect for the horizontal first condition (Figure 8A) and a negative effect in the vertical first condition (Figure 9A), 
which is in accordance with our expectations. Both these BFs are robust to changes in the prior width (Figure $8 B$, Figure $9 B$ ). Sequential analysis of the $B F$ in the horizontal first condition shows that it stabilizes around the $11^{\text {th }}$ data point, with a steady increase after (Figure $8 C$ ), whereas it almost immediately stabilizes to a steady increase in the vertical first condition (Figure 9C).
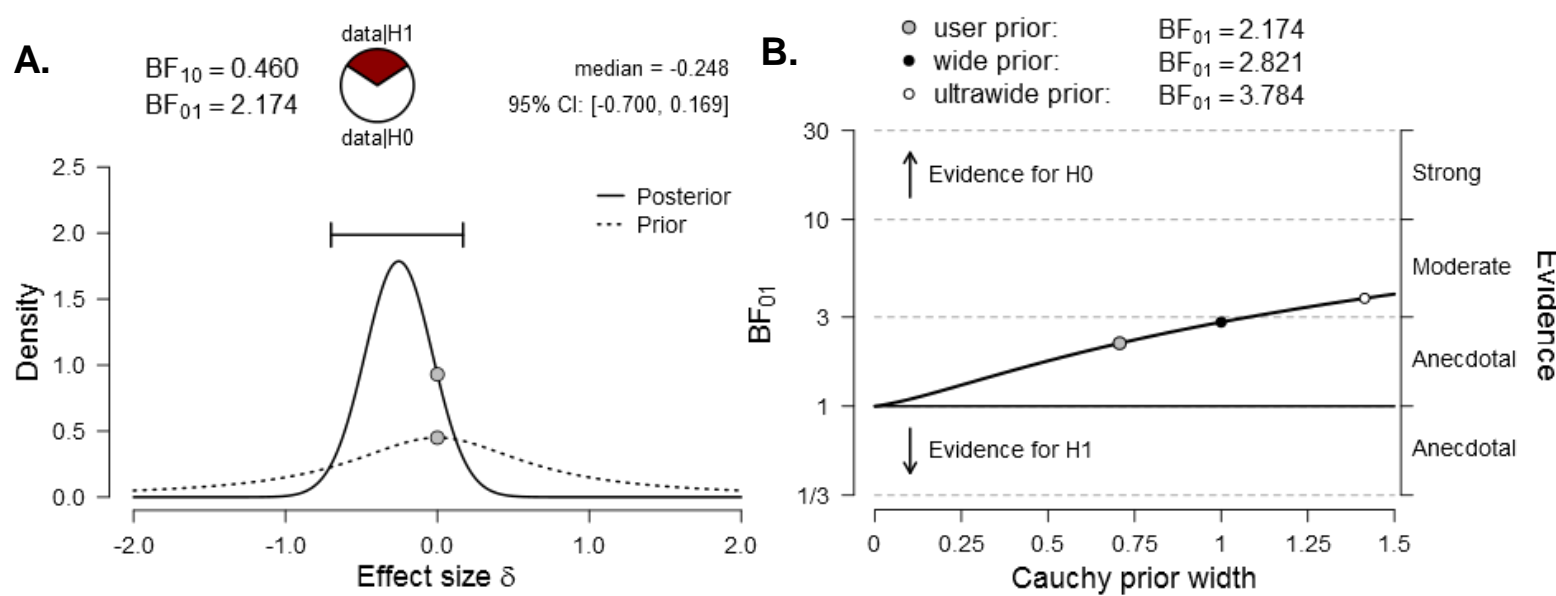

Note. Prior and posterior distribution of the Bayes factor $(B F)$

Note. Bayes factor $(B F)$ robustness check

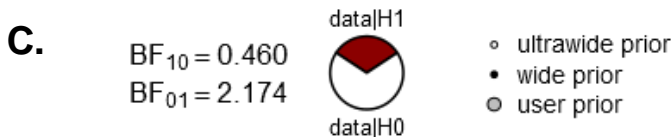

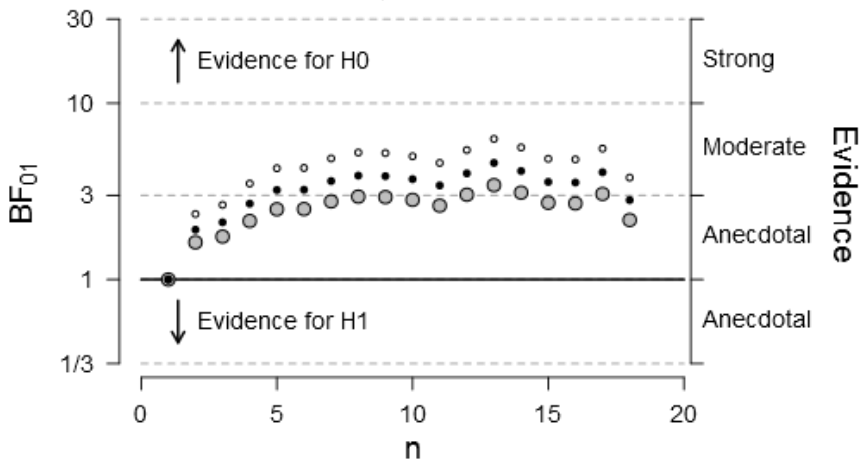

Note. Sequential analysis (combined with robustness check) of the Bayes factor $(B F)$

Figure 7. Bayesian one-sample $t$-test of the PSS in the no cue condition. 
A.

A. $\quad \mathrm{BF}_{10}=186.399$ $\mathrm{BF}_{01}=0.005$

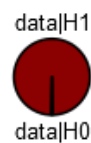

median $=1.027$

$95 \% \mathrm{Cl}:[0.430,1.640]$

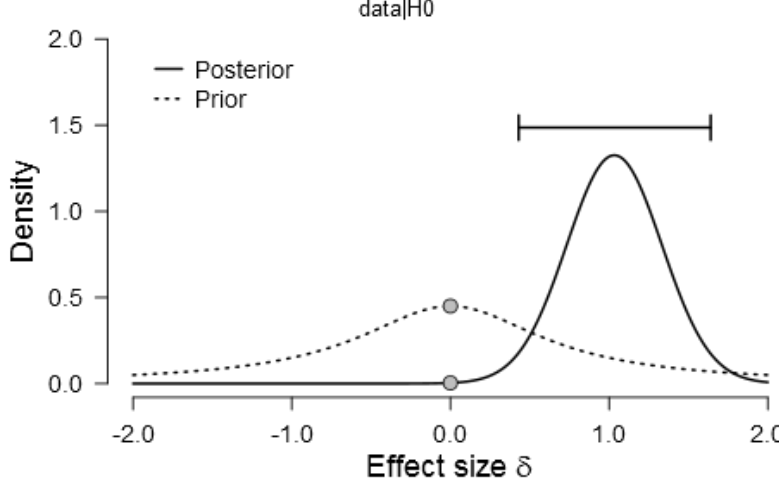

Note. Prior and posterior distribution of the

Bayes factor $(B F)$

C.
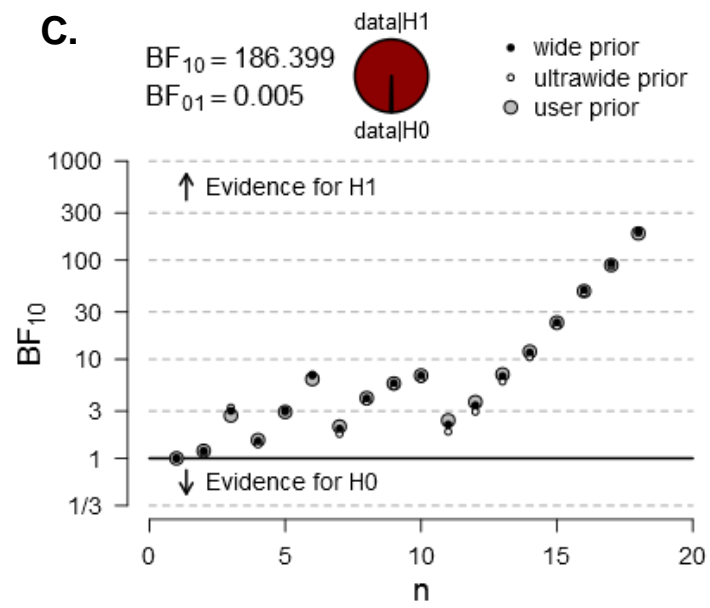

Note. Sequential analysis (combined with robustness check) of the Bayes factor $(B F)$

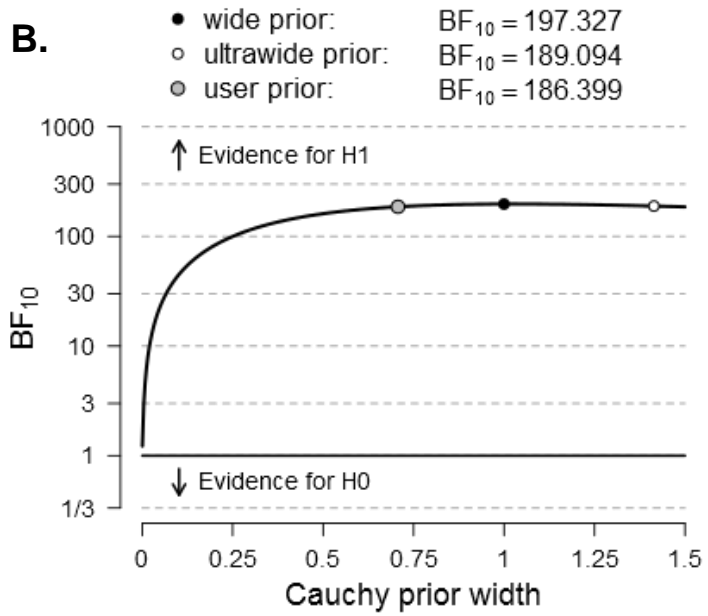

Note. Bayes factor $(B F)$ robustness check

Figure 8. Bayesian one-sample $t$-test of the PSS in the horizontal first condition. 


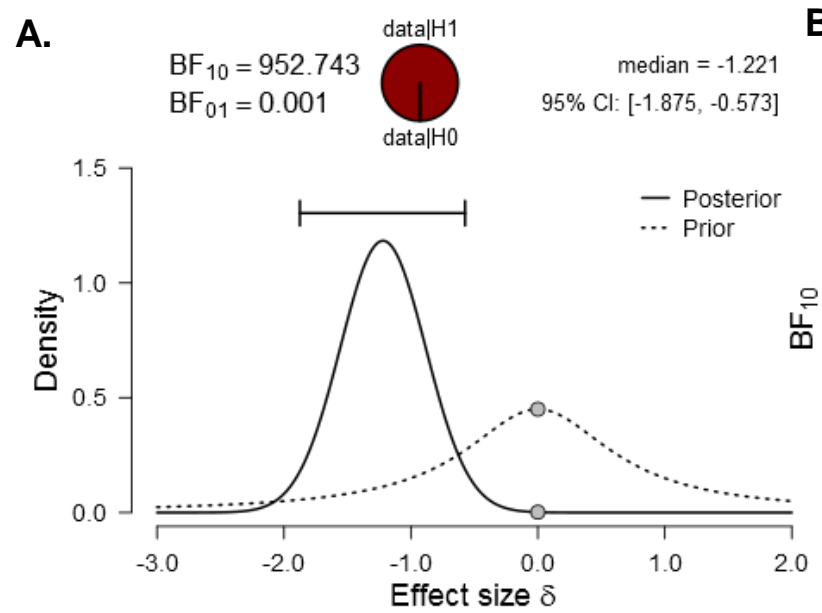

Note. Prior and posterior distribution of the Bayes Factor $(B F)$

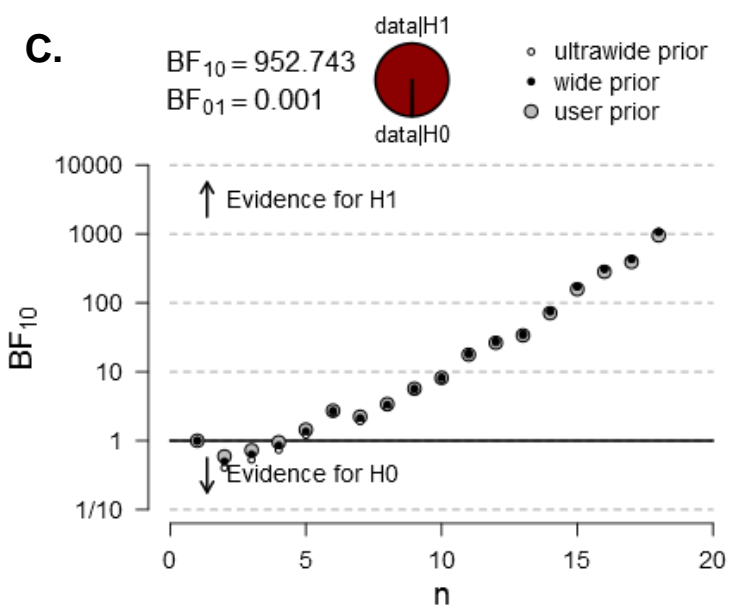

Note. Sequential analysis (combined with robustness check) of the Bayes factor $(B F)$

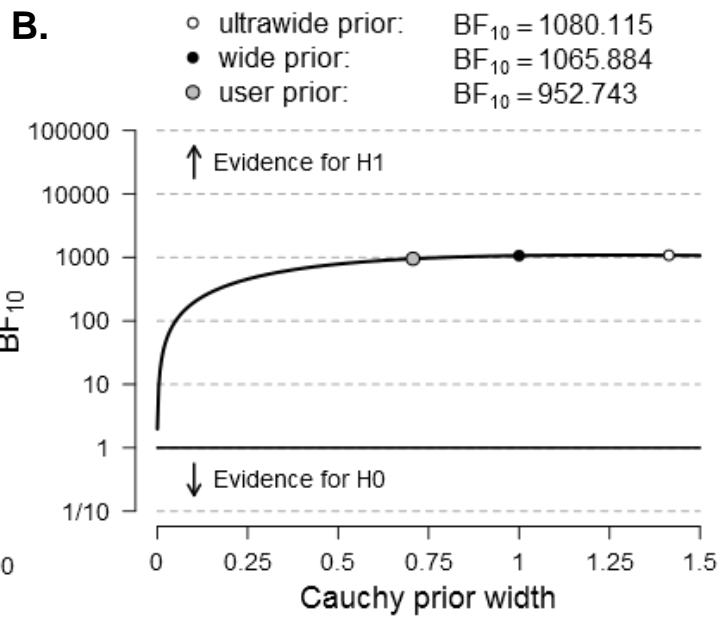

Note. Bayes factor $(B F)$ robustness check

Figure 9. Bayesian one sample $t$-test of the PSS in the vertical first condition.

\section{Paired samples $t$-tests}

Shapiro-Wilk's test revealed a deviation from normality for the difference between the vertical first and the no cue condition $(W=.74, p<.001)$, but no statistically significant evidence was found in favour of a violation of normality for the difference between the horizontal first and the no cue condition $(W=.97, p=.719)$. Paired samples $t$-tests determined that there was a statistically significant difference between the PSS in the horizontal first condition and the PSS in the no cue condition $\left(t_{17}=-4.77\right.$, $\left.p<.001, r=.76, \mathrm{CI}_{.95}[-71.3,-29.4]\right)$, as well as between the PSS in the vertical first condition and the PSS in the no cue condition $\left(t_{17}=4.78, p=.003, r=.76, \mathrm{CI}_{.95}[35.4\right.$, 74.2]) (Figure 6). Wilcoxon's signed-rank tests lead us to the same conclusions as the $t$ - 
tests (horizontal first vs. no cue: $T=9, p<.001, r=-.56$; vertical first vs. no cue: $T=$ $170, p<.001, r=.61)$.

A Bayesian paired samples $t$-test was conducted to compare the PSS in the horizontal first and the PSS in the no cue condition, which revealed very strong evidence in favour of a difference $\left(B F_{10}=170 \pm 0.00 \%\right)$ compared to the null (Figure 10A). Similar results were found for paired samples $t$-test between the PSS in the vertical first and the PSS in the no cue condition $\left(B F_{10}=173 \pm 0.00 \%\right)$ (Figure $\left.11 A\right)$. In both cases, these results were very robust against changes in the prior width (Figure 10B, Figure $11 B$ ). The BF steadily increased as the data accumulated. This increase was relatively stable in both cases (Figure 10C, Figure 11C).

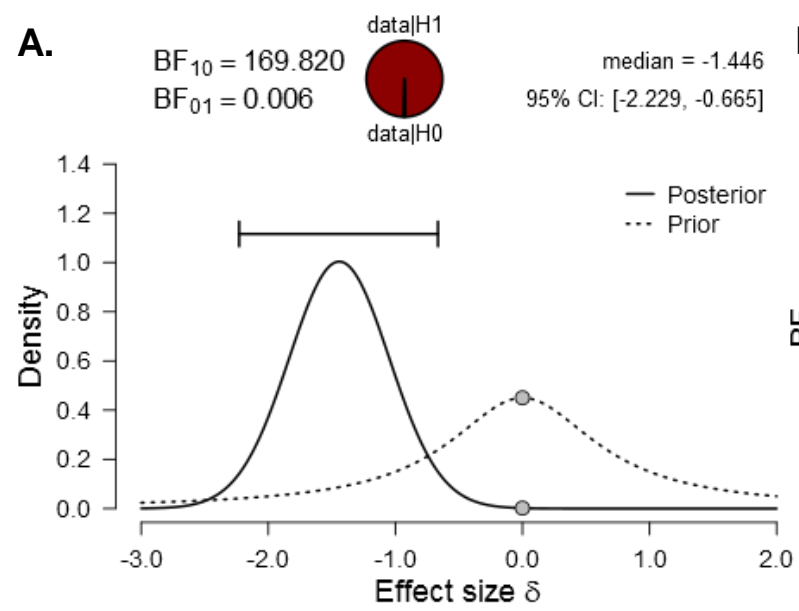

Note. Prior and posterior distribution of the

Bayes factor $(B F)$
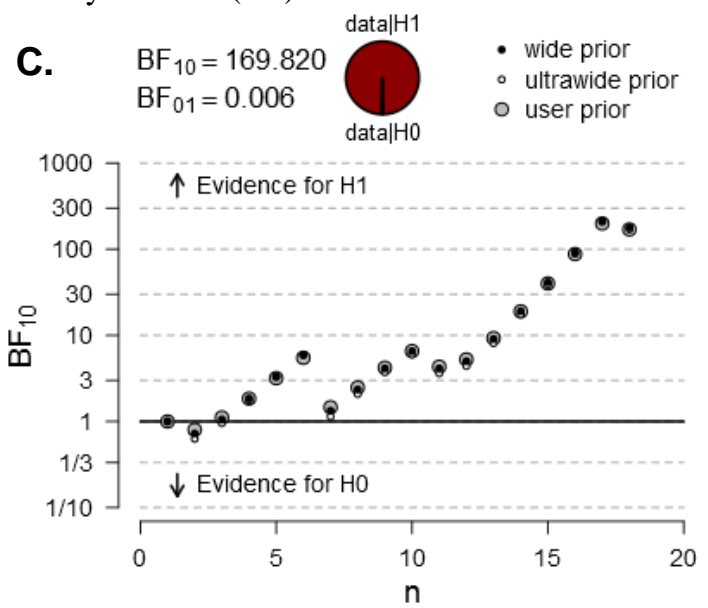

Note. Sequential analysis (combined with robustness check) of the Bayes factor $(B F)$

Figure 10. Bayesian paired samples $t$-test of PSS in no cue conditions and PSS in horizontal first conditions.

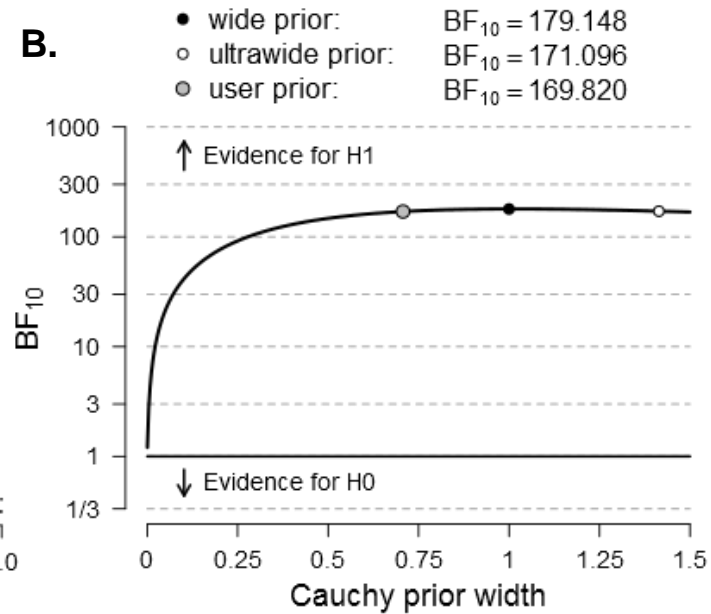

Note. Bayes factor $(B F)$ robustness check 
A.

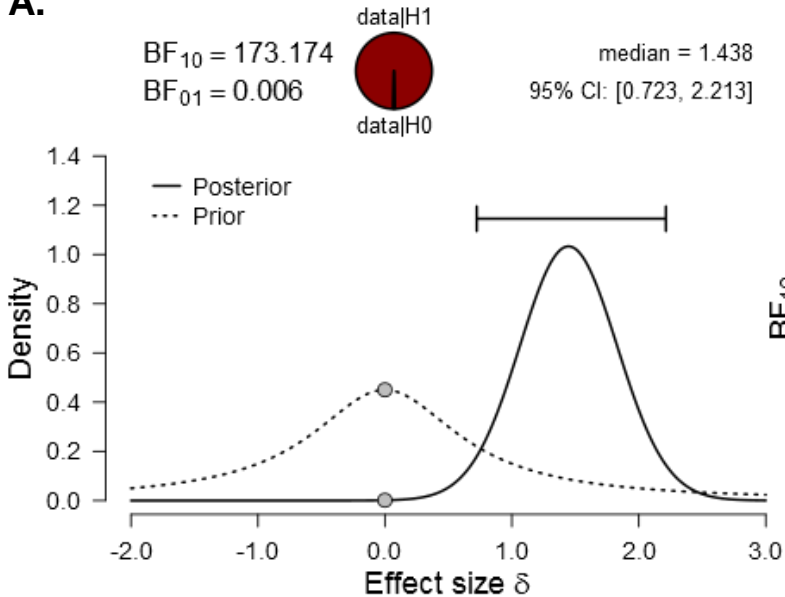

Note. Prior and posterior distribution of the Bayes factor $(B F)$

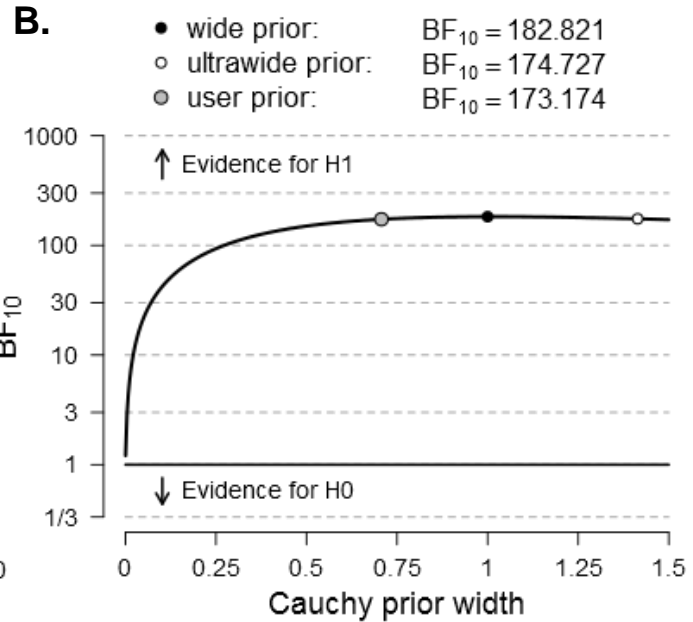

Note. Bayes factor $(B F)$ robustness check
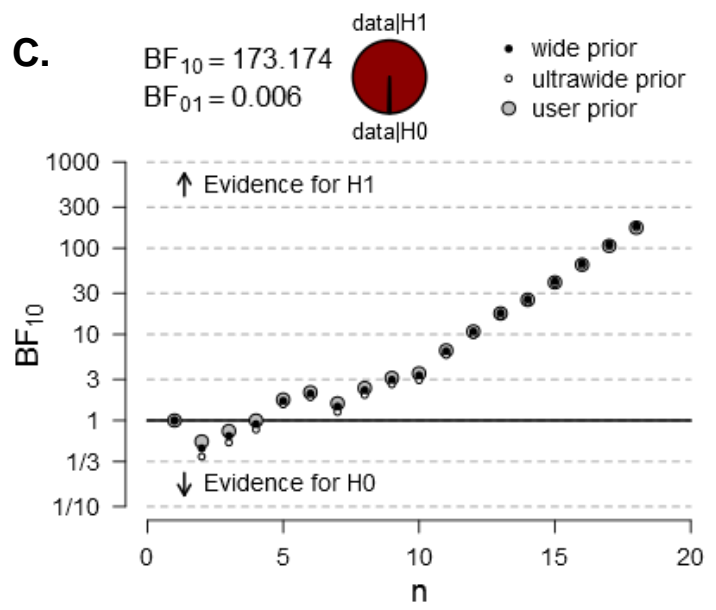

Note. Sequential analysis (combined with robustness check) of the Bayes factor $(B F)$

Figure 11. Bayesian paired samples t-test of PSS in no cue conditions and PSS in vertical first conditions. 


\section{Discussion}

The purpose of this thesis was to provide additional evidence for the hypothesis that attentional orienting towards non-reportable exogenous cues is an automatic process that occurs independently from attentional task sets. To investigate this research question, an experiment was conducted using a visual TOJ task in which participants were presented with two line gratings of opposite orientation on either side of a fixation cross, separated in time by various SOAs. The task was to judge the orientation of the line grating that was presented first. In two-thirds of the trials, the first line grating was preceded by the presentation of a non-reportable exogenous cue on that location.

The results showed a bias towards the line gratings presented at the cued location, particularly at short SOAs. These findings confirm that in conditions of maximal uncertainty, attended stimuli are consistently reported as being perceived before unattended ones, in accordance with the concept of prior entry (Schettino et al., 2016; Shore et al., 2001; Spence \& Parise, 2010; Titchener, 1908; Tünnermann et al., 2015; Tünnermann \& Scharlau, 2016).

This effect is very robust, since both parametrical and non-parametrical statistical procedures converged on similar results and were additionally confirmed by Bayes factor analyses. Importantly, by performing Bayesian factor analyses, we were not only able to quantify the amount of evidence in favour of the effect under scrutiny, but we could also quantify the evidence in favour of the null hypothesis, something that cannot be achieved by means of NHST (Dienes, 2011; Etz et al., 2017; Rouder et al., 2009; Wagenmakers, 2007). Although the evidence in favour of a bias was very strong in the cued conditions, the evidence in favour of no effect in the no cue condition seemed weaker. Nonetheless, the results of paired-samples $t$-tests showed a distinct bias towards the cued conditions compared to the no cue condition.

Non-attentional confounds, such as strategic decision criteria, response biases, and primary sensory facilitation (K. A. Schneider \& Bavelier, 2003), were minimized by meticulously tuning the experimental parameters. Furthermore, the experiment was conducted in such a way that the effect cannot be attributed to the influence of attentional task set. Attending to the cued location was counterproductive, given that the cued location was always opposite to the location of the first line grating. If attentional task set did play a role, and the nature of the orienting response was endogenous (i.e., 
feature contingent) (Ansorge et al., 2011; Folk et al., 1992), we would expect participants to be able to ignore the cue (Ansorge \& Neumann, 2005; Held et al., 2010; Scharlau \& Ansorge, 2003) and, consequently, we would not have seen a bias towards the cued location. In addition, Schettino et al. (2016) already provided behavioural and electrophysiological evidence (using a similar task) that goal-related attentional task set does not play a role in orienting towards exogenous cues. Taken together, these findings suggest that the presence of a top-down attentional task set is not imperative for the occurrence of an orienting response towards non-reportable exogenous cues. As such, this effect in turn meets one of the main criteria of bottom-up or exogenous attention (Jonides, 1981). Thus, it can be considered evidence in favour of an automatic nature of the orienting response (see also Ansorge et al., 2011).

Another point of interest in this thesis was the awareness of the exogenous cue, since we wanted to provide evidence for involuntary orienting independent from awareness (McCormick, 1997; Mulckhuyse et al., 2007). During the instructions, participants were informed about the presence of the cue, but were instructed to ignore it and focus on the task instead. Results showed that it is unlikely that they were able to detect the cue.

We did, however, find very strong evidence for a bias towards responding "no" to the question whether they had seen the cue. This observation is in line with the results reported in Schettino et al. (2016) when using a different criterion parameter ( $\beta$ instead of $c$; see Stanislaw and Todorov, 1999). This response bias may originate from a strategic decision process in which participants, when uncertain of having perceived the cue, judged more often to not have seen it, since they were told to ignore it and focus on the task. Nonetheless, the fact that participants were more likely to report not having seen the cue even though it was presented on such a large portion of the trials (i.e., twothirds), suggests that they were not able to reliably detect it.

It is important to note that, by providing participants with prior information about the cue (i.e., what the cue would look like), the endogenous attentional sensitivity to the cue features was increased prior to presentation, facilitating the consolidation process (Kiefer et al., 2011). Regardless of this top-down attentional amplification of the cue representation, participants could still not reliably report the occurrence of the exogenous cue. 
One may argue that the cue employed here is not purely exogenous. Previously, we defined a purely exogenous cue as being uninformative and unpredictable. Here, the cue was inherently informative in the sense that it indicated the location where the first line grating would not be presented. This makes the cue task-relevant and, therefore, it cannot be considered purely exogenous. Previous research (Ansorge et al., 2011; Folk et al., 2012) would claim that attentional capture can be achieved only if the nonreportable cue is task-relevant. This would increase its salience and therefore, attention would be attracted to it even more (Kiefer et al., 2011). However, as mentioned before, Schettino et al. (2016) already provided evidence that top-down attentional task set does not play a role in orienting towards exogenous cues ${ }^{8}$. In this experiment, the cue was task-relevant in two ways: (i) participants were instructed to ignore the cue, since it would not help their performance at the task. (ii) on some trials, participants had to report whether or not they had perceived the cue. If the cue truly is informative, we would expect the brain to comprehend the information it conveys, otherwise, it would be no more than an uninformative flash. The cue revealed that, when it is presented, the target (i.e., the first line grating) will be presented on the opposite location. Therefore, the best strategy to adopt would be to simply ignore the cue. However, this information is presumably not detected by the brain, since attention is consistently attracted to the cued location. Considering perception is actively biased by the cue, its information has been actively used by the visual system to influence attention. So, the cue is apparently treated as a relevant and informative event, even though being fully invalid and unconscious. This, in combination with the results of a previous study (Schettino et al., 2016), suggests that attentional capture (at least in TOJ paradigms) is likely to be bottom-up.

It should be noted that the stimuli that were employed here are quite simple in comparison to the stimuli we are confronted with in everyday life. Moreover, the complex environments that we typically navigate on a daily basis usually stimulate multiple sensory modalities (instead of only one modality), and are usually related to one another in a meaningful manner when presented to us in temporal proximity. Given

\footnotetext{
${ }^{8}$ Please also note that this study is only the pilot of an ongoing project aimed at investigating the boundary conditions of prior entry phenomena in a series of 4 separate experiments.
} 
that attention is automatically directed towards abrupt stimuli in reasonably simple and controlled environments such as in this experiment, it is feasible to imagine the consequences it can have in much more complex sensory situations.

For instance, driving a vehicle involves activating and coordinating a complex set of tasks. And while driving, we are bombarded with sensory inputs from various modalities that require our attention, with vision being the most important modality when it comes to driving safely. The impact of even a brief and unconscious visual distraction (e.g., a brief blink on your cell phone screen as a text message arrives) can be detrimental. Everyone who has ever been in an accident or has witnessed one, knows that it can happen in a fraction of a second. However, it can also have positive implications: as a driver, you always need to be prepared to respond to the unexpected. Abrupt changes in our environment can indicate potential hazards and attending to them can facilitate a quick response, in time to avoid a crash. But it is the tiny stimulations that are not relevant to the task at hand, that are the real cause for concern. If they can grab attention so powerfully, it seems logical that larger distractions (e.g., texting while driving) lead to more critical visual cues being missed. This not only applies to driving, but can be extrapolated to all situations where visual attention is crucial (e.g., operating heavy machinery). Given the impact phenomena such as abrupt onsets can have on our daily life, it is essential to continue researching these phenomena to gain a deeper understanding of their workings and consequently, their effects.

In conclusion, here we have found further behavioural evidence that orienting towards non-reportable exogenous cues truly is an involuntary process that one cannot easily suppress, even though it proves to be counterproductive. This has some meaningful practical implications with regards to the effect of unconscious visual distractions in perceptually demanding tasks. 


\section{Nederlandstalige Samenvatting}

Binnen de literatuur is er een debat gaande met betrekking tot de aard van het richten van aandacht naar onbewuste exogene cues. Er wordt beweerd dat hoewel het richten van aandacht naar bewuste stimuli wel bottom-up kan verlopen, dit in het geval van onbewuste stimuli consistent gemoduleerd wordt door endogene factoren. Dit zou suggereren dat een zuiver exogene aandachtsverschuiving naar onbewuste stimuli mogelijks niet bestaat. In deze thesis beoogden we overtuigend bewijs te leveren voor een onwillekeurige aard van aandachtsverschuivingen naar onbewuste cues, onafhankelijk van endogene factoren zoals taakset. Om dit te bestuderen werd een experiment uitgevoerd waarin het temporele orde waarnemingsparadigma (TOJ) werd aangewend. Hierbij werden twee lijnroosters van tegengestelde oriëntatie gepresenteerd aan weerszijde van een fixatie, gescheiden door verschillende stimulus onset asynchronies (SOAs). De taak van de participanten bestond eruit om de oriëntatie van het lijnrooster dat eerst gepresenteerd werd te rapporteren. In twee-derde van de trials werd er een niet-waarneembare exogene cue gepresenteerd op de tegenovergestelde locatie van het eerste lijnrooster, waardoor het contraproductief zou zijn om de aandacht naar de locatie van de cue te richten. Naast prestatie op de TOJ taak, werd ook bewustzijn van de cue onderzocht. De data werd geanalyseerd aan de hand van zowel parametrische als non-parametrische procedures, aangevuld met Bayes factor analyses. De resultaten van al deze procedures toonden een systematische afwijking naar de lijnroosters die voorafgegaan werden door de cues. Dit suggereert dat bottom-up aandachtsverschuivingen naar onbewuste exogene cues plaatsgrijpen onafhankelijk van de taakset. 


\section{References}

Ansorge, U., Horstmann, G., \& Scharlau, I. (2011). Top-down contingent featurespecific orienting with and without awareness of the visual input. Advances in Cognitive Psychology, 7(1), 108-119.

Ansorge, U., \& Neumann, O. (2005). Intentions determine the effect of invisible metacontrast-masked primes: evidence for top-down contingencies in a peripheral cuing task. Journal of Experimental Psychology: Human Perception and Performance, 31(4), 762-777.

Cohen, J. (1992). A power primer. Psychological Bulletin, 112(1), 155-159.

Corbetta, M., \& Shulman, G. L. (2002). Control of goal-directed and stimulus-driven attention in the brain. Nature Reviews Neuroscience, 3(3), 215-229.

Di Russo, F., Martínez, A., \& Hillyard, S. A. (2003). Source analysis of event-related cortical activity during visuo-spatial attention. Cerebral Cortex, 13(5), 486-499.

Dienes, Z. (2011). Bayesian Versus Orthodox Statistics: Which Side Are You On? Perspectives on Psychological Science, 6(3), 274-290.

Efron, B. (1987). Better bootstrap confidence intervals. Journal of the American Statistical Association, 82(397), 171-185.

Efron, B., \& Tibshirani, R. J. (1993). An Introduction to the Bootstrap: Monographs on Statistics and Applied Probability (Vol. 57). New York: Chapman and Hall/CRC.

Egeth, H. E., \& Yantis, S. (1997). Visual attention: Control, representation, and time course. Annual Review of Psychology, 48(1), 269-297.

Eriksen, C. W., \& Collins, J. F. (1969). Temporal course of selective attention. Journal of Experimental Psychology, 80(2), 254-261.

Etz, A., Gronau, Q. F., Dablander, F., Edelsbrunner, P. A., \& Baribault, B. (2017). How to become a Bayesian in eight easy steps: An annotated reading list. Psychonomic Bulletin \& Review.

Fendrich, R., \& Corballis, P. M. (2001). The temporal cross-capture of audition and vision. Perception \& Psychophysics, 63(4), 719-725.

Folk, C. L., Remington, R. W., \& Johnston, J. C. (1992). Involuntary covert orienting is contingent on attentional control settings. Journal of Experimental Psychology Human Perception and Performance, 18(4), 1030-1044. 
Frey, R. D. (1990). Selective attention, event perception and the criterion of acceptability principle: Evidence supporting and rejecting the doctrine of prior entry. Human Movement Science, 9(3-5), 481-530.

Fu, S., Greenwood, P. M., \& Parasuraman, R. (2005). Brain mechanisms of involuntary visuospatial attention: An event-related potential study. Human Brain Mapping, 25(4), 378-390.

Gigerenzer, G. (2004). Mindless statistics. The Journal of Socio-Economics, 33(5), 587606.

Green, D. M., \& Swets, J. A. (1966). Signal Detection Theory and Psychophysics. New York: Wiley.

Hautus, M. J. (1995). Corrections for extreme proportions and their biasing effects on estimated values of d'. Behavior Research Methods, 27(1), 46-51.

Held, B., Ansorge, U., \& Müller, H. J. (2010). Masked singleton effects. Attention, Perception, \& Psychophysics, 72(8), 2069-2086.

Hickey, C., Chelazzi, L., \& Theeuwes, J. (2010). Reward Changes Salience in Human Vision via the Anterior Cingulate. Journal of Neuroscience, 30(33), 1109611103.

Hickey, C., \& van Zoest, W. (2013). Reward-associated stimuli capture the eyes in spite of strategic attentional set. Vision Research, 92, 67-74.

Hommel, B. (2011). The Simon effect as tool and heuristic. Acta Psychologica, 136(2), 189-202.

Honaker, J., \& King, G. (2010). What to do about missing values in time-series crosssection data. American Journal of Political Science, 54(2), 561-581.

Honaker, J., King, G., \& Blackwell, M. (2013). Amelia II: a program for missing data.

Hughes, H. C. (1984). Effects of flash luminance and positional expectancies on visual response latency. Perception \& Psychophysics, 36(2), 177-184.

IBM Corp. (2013). IBM SPSS Statistics for Windows, Version 23.0. Armonk, NY: IBM Corp.

James, W. (1890). The principles of psychology. New York: H. Holt and Company.

JASP Team. (2017). JASP, Version 0.8.1.2 [Computer software]. 
Jonides, J. (1981). Voluntary versus automatic control over the mind's eye. In J. B. Long \& A.D. Baddeley (Eds.), Attention and performance IX, (pp. 187-203). Hillsdale, NJ: Erlbaum.

Kiefer, M., Ansorge, U., Haynes, J.-D., Hamker, F., Mattler, U., Verleger, R., \& Niedeggen, M. (2011). Neuro-cognitive mechanisms of conscious and unconscious visual perception: From a plethora of phenomena to general principles. Advances in Cognitive Psychology, 7(1), 55-67.

Lakens, D. (2013). Calculating and reporting effect sizes to facilitate cumulative science: a practical primer for $t$-tests and ANOVAs. Frontiers in Psychology, 4.

McCormick, P. A. (1997). Orienting attention without awareness. Journal of Experimental Psychology: Human Perception and Performance, 23(1), 168180.

McDonald, J. J., Teder-Sälejärvi, W. A., Di Russo, F., \& Hillyard, S. A. (2005). Neural basis of auditory-induced shifts in visual time-order perception. Nature Neuroscience, 8(9), 1197-1202.

Moseley, G. L., Gallace, A., \& Spence, C. (2009). Space-based, but not arm-based, shift in tactile processing in complex regional pain syndrome and its relationship to cooling of the affected limb. Brain, 132(11), 3142-3151.

Mulckhuyse, M., Talsma, D., \& Theeuwes, J. (2007). Grabbing attention without knowing: Automatic capture of attention by subliminal spatial cues. Visual Cognition, 15(7), 779-788.

Mulckhuyse, M., \& Theeuwes, J. (2010). Unconscious attentional orienting to exogenous cues: A review of the literature. Acta Psychologica, 134(3), 299-309.

Posner, M. I. (1980). Orienting of attention. Quarterly Journal of Experimental Psychology, 32(1), 3-25.

Posner, M. I., Snyder, C. R., \& Davidson, B. J. (1980). Attention and the detection of signals. Journal of Experimental Psychology: General, 109(2), 160-174.

R. Core Team. (2015). R: A language and environment for statistical computing. Vienna, Austria: R Foundation for Statistical Computing.

Raftery, A. E. (1995). Bayesian model selection in social research. Sociological Methodology, 25, 111-163. 
Ramsøy, T. Z., \& Overgaard, M. (2004). Introspection and subliminal perception. Phenomenology and the Cognitive Sciences, 3(1), 1-23.

Rouder, J. N., Speckman, P. L., Sun, D., Morey, R. D., \& Iverson, G. (2009). Bayesian t tests for accepting and rejecting the null hypothesis. Psychonomic Bulletin \& Review, 16(2), 225-237.

Scharlau, I., \& Ansorge, U. (2003). Direct parameter specification of an attention shift: Evidence from perceptual latency priming. Vision Research, 43(12), 1351-1363.

Schettino, A., Loeys, T., \& Pourtois, G. (2013). No prior entry for threat-related faces: Evidence from temporal order judgments. PloS One, 8(4), e62296.

Schettino, A., Rossi, V., Pourtois, G., \& Müller, M. M. (2016). Involuntary attentional orienting in the absence of awareness speeds up early sensory processing. Cortex, 74, 107-117.

Schneider, K. A., \& Bavelier, D. (2003). Components of visual prior entry. Cognitive Psychology, 47(4), 333-366.

Schneider, W., Eschman, A., \& Zuccolotto, A. (2002). E-Prime: User's guide. Pittsburgh, PA.: Psychology Software Incorporated.

Serences, J. T., Shomstein, S., Leber, A. B., Golay, X., Egeth, H. E., \& Yantis, S. (2005). Coordination of voluntary and stimulus-driven attentional control in human cortex. Psychological Science, 16(2), 114-122.

Shapiro, S. S., \& Wilk, M. B. (1965). An analysis of variance test for normality (complete samples). Biometrika, 52(3/4), 591-611.

Shore, D. I., Spence, C., \& Klein, R. M. (2001). Visual Prior Entry. Psychological Science, 12(3), 205-212.

Simon, J. R., \& Rudell, A. P. (1967). Auditory SR compatibility: the effect of an irrelevant cue on information processing. Journal of Applied Psychology, 51(3), 300-304.

Spence, C., \& Parise, C. (2010). Prior-entry: A review. Consciousness and Cognition, 19(1), 364-379.

Stanislaw, H., \& Todorov, N. (1999). Calculation of signal detection theory measures. Behavior Research Methods, Instruments, \& Computers, 31(1), 137-149. 
Stelmach, L. B., \& Herdman, C. M. (1991). Directed attention and perception of temporal order. Journal of Experimental Psychology: Human Perception and Performance, 17(2), 539-550.

Sternberg, S., \& Knoll, R. L. (1973). The perception of temporal order: Fundamental issues and a general model. In S. Kornblum (Ed.), Attention and Performance IV, (pp. 629-685). New York: Academic Press.

Theeuwes, J. (1994). Endogenous and Exogenous Control of Visual Selection. Perception, 23(4), 429-440.

Titchener, E. B. (1908). Lectures on the elementary psychology of feeling and attention. New York: Macmillan.

Treisman, A., \& Schmidt, H. (1982). Illusory conjunctions in the perception of objects. Cognitive Psychology, 14(1), 107-141.

Tünnermann, J., Petersen, A., \& Scharlau, I. (2015). Does attention speed up processing? Decreases and increases of processing rates in visual prior entry. Journal of Vision, 15(3), 1-27.

Tünnermann, J., \& Scharlau, I. (2016). Peripheral Visual Cues: Their Fate in Processing and Effects on Attention and Temporal-Order Perception. Frontiers in Psychology, 7(1442).

Verleger, R., Żurawska vel Grajewska, B., \& Jaśkowski, P. (2012). Time-course of hemispheric preference for processing contralateral relevant shapes: P1pc, N1pc, N2pc, N3pc. Advances in Cognitive Psychology, 8(1), 19-28.

Vibell, J., Klinge, C., Zampini, M., Spence, C., \& Nobre, A. C. (2007). Temporal Order is Coded Temporally in the Brain: Early Event-related Potential Latency Shifts Underlying Prior Entry in a Cross-modal Temporal Order Judgment Task. Journal of Cognitive Neuroscience, 19(1), 109-120.

Wagenmakers, E.-J. (2007). A practical solution to the pervasive problems ofp values. Psychonomic Bulletin \& Review, 14(5), 779-804.

Wagenmakers, E.-J., Love, J., Marsman, M., Jamil, T., Ly, A., Verhagen, J., ... Morey, R. D. (2017). Bayesian inference for psychology. Part II: Example applications with JASP. Psychonomic Bulletin \& Review.

Wascher, E., \& Beste, C. (2010). Tuning Perceptual Competition. Journal of Neurophysiology, 103(2), 1057-1065. 
Weiß, K., \& Scharlau, I. (2012). At the mercy of prior entry: Prior entry induced by invisible primes is not susceptible to current intentions. Acta Psychologica, $139(1), 54-64$.

Wetzels, R., Matzke, D., Lee, M. D., Rouder, J. N., Iverson, G. J., \& Wagenmakers, E.J. (2011). Statistical Evidence in Experimental Psychology: An Empirical Comparison Using $855 t$ Tests. Perspectives on Psychological Science, 6(3), 291-298.

Wilcoxon, F. (1945). Individual comparisons by ranking methods. Biometrics bulletin, 1(6), 80-83. 